\title{
Documento de consenso sobre la utilización de profilaxis antibiótica en cirugía y procedimientos dentales
}

\section{Consensus document on the use of antibiotic prophylaxis in dental surgery and procedures}

\author{
J.L. Gutiérrez', J. Vicente Bagán'2, A. Bascones 3 , R. Llamas4, J. Llena', A. Morales', B. Noguerol', \\ P. Planells 8 , J. Prieto9 , J.I. Salmerón ${ }^{10}$
}

Resumen: La profilaxis antibiótica en Odontología tiene como objetivo prevenir la aparición de infección a partir de la puerta de entrada que produce la actuación terapéutica, por lo que se encuentra indicada siempre que exista un riesgo importante de infección, ya sea por las características mismas de la operación o por las condiciones locales o generales del paciente. Sin embargo, los ensayos clínicos con antibióticos en patologías dentarias responden poco a los criterios metodológicos requeridos, y además no son lo suficientemente numerosos.

Se presentan los resultados de una conferencia de expertos integrada por los Presidentes de Sociedades Científicas Españolas más representativas que han analizado la bibliografía existente y han aportado sus valiosas experiencias profesionales. Se describen las circunstancias técnicas, se analizan los fundamentos biológicos y farmacológicos y se aplican a las situaciones médicas más representativas. Se concluye que la profilaxis antibiótica en Odontología cuenta con indicaciones bien fundamentadas y precisas, ofreciendo a la comunidad científica internacional un protocolo práctico de actuación.

Palabras clave: Profilaxis; Antibióticos; Odontología.

\begin{abstract}
The goal of antibiotic prophylaxis in Odontology is to prevent the onset of infections through the entranceway provided by the therapeutic action, therefore it is indicated providing there is a considerable risk of infection, either because of the characteristics of the operation itself or the patient's local or general condition. Nonetheless, clinical trials with antibiotics in dental pathologies have had scant regard for the required methodological criteria and, in addition, are not sufficiently numerous. This text presents the results of an expert conference comprising the Presidents of the most representative Scientific Societies in Spain who have analyzed the existing literature and have drawn on their valuable professional experience. It describes the technical circumstances, analyzes the biological and pharmacological foundations and their application to the most representative medical situations. It is concluded that antibiotic prophylaxis in Odontology has certain well-founded, precise indications and offers the international scientific community a practical protocol for action.
\end{abstract}

Key words: Prophylaxis; Antibiotics; Dentistry.

Recibido: 13.06 .2006

Aceptado: 14.06 .2006

\footnotetext{
1 Sociedad Española de Cirugía Bucal

2 Director de la Revista Medicina Oral, Patología Oral, Cirugía Bucal

3 Sociedad Española de Medicina Oral

4 Sociedad Española de Odontología Conservadora

5 Sociedad Española de Prótesis Estomatológica

6 Sociedad Española de Implantología

7 Sociedad Española de Periodoncia

8 Sociedad Española de Odontopediatría

9 Sociedad Española de Quimioterapia

10 Sociedad Española de Cirugía Oral y Maxilofacial

Correspondencia:

José Luis Gutiérrez Pérez

Servicio de Cirugía Maxilofacial. Hospital Virgen del Rocío

$\mathrm{Av} /$ Manuel Siurot $\mathrm{s} / \mathrm{n}$

41013 Sevilla. España

E-mail: jlgp@us.es
} 


\section{Introducción}

Clásicamente se ha considerado la profilaxis como la administración pre- o peri-operatoria de un antibiótico para la prevención de una complicación infecciosa local y/o sistémica y sus correspondientes consecuencias clínicas.

La finalidad de la profilaxis antibiótica en cirugía es prevenir la posible aparición de infección a nivel de la herida quirúrgica, creando un estado de resistencia a los microorganismos mediante concentraciones antibióticas en sangre que eviten la proliferación y diseminación bacteriana a partir de la puerta de entrada que representa la herida quirúrgica.

El $10 \%$ de las prescripciones antibióticas realizadas en nuestro país se utiliza para infecciones odontogénicas, y una parte significativa de ellas para profilaxis en cirugía y procedimientos dentales. ${ }^{1}$ Al igual que las recomendaciones acerca de la utilización de los antibióticos en el tratamiento de infecciones odontogénas, las recomendaciones de la profilaxis antibiótica no pueden basarse en ensayos clínicos (ni por ende, en la Medicina Basada en la Evidencia), ya que los ensayos clínicos con antibióticos en patologías dentarias responden poco a los criterios metodológicos requeridos, y además no son lo suficientemente numerosos para establecer una conducta. Por ello la estrategia general de prescripción antibiótica terapéutica o profiláctica se basa en acuerdos profesionales y documentos de consenso.

Las recomendaciones propuestas en este documento están basadas en el consenso de los profesionales que han participado en el desarrollo del mismo.

\section{Fundamentos teóricos}

\section{Complicaciones a evitar}

Las infecciones locales polimicrobianas son infecciones cutáneo-mucosas, dentales u óseas que se favorecen como consecuencia de procedimientos dentales invasivos, ${ }^{2}$ y que se traducen clínicamente en flemones, abscesos, pérdida de dientes, pérdida implantaria o de la estructura protésica. En un estudio llevado a cabo en nuestro país se demostró que las complicaciones subsiguientes a la extracción del tercer molar son una enfermedad infecciosa y no exclusivamente inflamatoria, ya que se encontraron diferencias estadísticamente significativas en la frecuencia de complicaciones infecciosas entre los grupos que recibieron tratamiento preventivo (5 días) o profilaxis preoperatoria (dosis única) con amoxicilina/ácido clavulánico 2000/125 mg, y el grupo que recibió placebo $\left(2,7 ; 5,3\right.$ y $16 \%$ respectivamente). ${ }^{3}$ Las tasas de complicación infecciosa eran mayores en caso de osteotomía o mayor duración del acto quirúrgico, siendo en estos casos claramente mejor el tratamiento que la profilaxis o el placebo. El inóculo infectante aumenta conforme se prolonga el tiempo del acto quirúrgico. Así la probabilidad de infección alrededor de los implantes dentales depende fundamentalmente de lo traumática o prolongada que sea la cirugía, ${ }^{4}$ considerándose que las poco frecuentes pérdidas precoces del implante, ${ }^{5}$ se deben a la contaminación durante la fase de inserción del mismo. ${ }^{6}$

\section{Introduction}

Prophylaxis has been considered traditionally as the preor peri- operative administration of an antibiotic for the prevention of a local and/or systemic infectious complication and the corresponding clinical consequences.

The aim of antibiotic prophylaxis in surgery is to prevent the possible appearance of infection in the surgical wound by creating a state of resistance to microorganisms by means of a concentration of antibiotic in blood serum that avoid bacterial proliferation and dissemination as from the point of entry represented by the surgical wound.

Of the antibiotic prescriptions in our country, $10 \%$ are used for odontogenic infections, and of this a significant part is used for prophylaxis in dental surgery and procedures. ${ }^{1}$ The recommendations for antibiotic prophylaxis, just as those concerning the use of antibiotics for treating odontogenic infections, cannot be based on clinical trials (nor on Evidence Based Medicine), as in clinical trials with antibiotics for dental pathologies there is little response to the required methodological criteria, and in addition to this, they are not numerous enough to establish a code of conduct. Therefore, the general strategy for the therapeutic or prophylactic prescription of antibiotics is based on professional agreements and consensus documents. The recommendations proposed in this document are based on the consensus of the professionals who participated in its development.

\section{Theoretical bases}

\section{Complications to avoid}

Local polymicrobial infections are cutaneous-mucosal, dental or bone infections that are favored as a result of invasive dental procedures ${ }^{2}$ and, that translate clinically into inflammations, abscesses, loss of teeth, implants or prosthetic structures. In a study carried out in our country, it was demonstrated that the complications following the extraction of third molars are infectious and not just inflammatory, as statistically significant differences in the frequency of infectious complications were found in the groups that received preventative treatment (5 days) or preoperative prophylaxis (single dose) with amoxicillin/clavulanic acid 2000/125 mg, and the group that received a placebo $\left(2.7,5.3\right.$ and $16 \%$ respectively). ${ }^{3}$ The rate of infectious complications was greater following osteotomies or longer surgical procedures, with treatment being clearly better than prophylaxis or a placebo. Thus, the probability of infection around dental implants depends fundamentally on how traumatic or prolonged the surgery is, ${ }^{4}$ and it is considered that the early loss of implants, ${ }^{5}$ though infrequent, is due to contamination during the insertion phase. ${ }^{6}$ Monomicrobial systemic infections are the infections that are established in patients with a focal point that is more susceptible to infection (endocardial disorders, bone or joint prostheses), in patients that are more susceptible to systemic infec- 
Las infecciones sistémicas monomicrobianas son las infecciones que asientan en pacientes con focalidad susceptible de infectarse (alteraciones endocárdicas, prótesis óseas o articulares), en pacientes con mayor susceptibilidad para la infección sistémica por determinados microorganismos (pacientes esplenectomizados e infección por bacterias capsuladas del género Streptococcus o Haemophilus), o en pacientes con alteraciones generalizadas del sistema inmune que faciliten una septicemia (inmunodeprimidos, inmunocomprometidos y desnutridos). Generalmente, el primer paso suele ser la bacteriemia, que se produce tras un procedimiento invasivo. Esta bacteriemia se encuentra bien estudiada en la muy prevalente enfermedad periodontal (periodontitis), debido a la permeabilidad del epitelio que rodea la interfase diente-tejido, y a los niveles de prostaglandinas en la circulación local que incrementan el número de leucocitos y niveles de fibrinógeno, enlentenciendo la circulación en estos casos, lo que favorece el paso de bacterias a sangre. ${ }^{7}$ Así en modelos animales, la endocarditis subsiguiente a bacteriemia es del $48 \%$ en ratas con enfermedad periodontal versus un $6 \%$ en ratas sanas. ${ }^{8}$ En humanos, la bacteriemia subsiguiente a procedimientos invasivos se sitúa en un $51-55 \% .^{9}$

\section{Balance Coste-Beneficio}

El criterio del facultativo para la elección o no de profilaxis antibiótica debe basarse en el concepto de coste riesgo-beneficio. El coste económico de las maniobras profilácticas (que son usualmente de curso corto) es satisfactorio cuando se compara con el coste total del tratamiento odontológico. Evidentemente el beneficio es la prevención por parte del antibiótico de las complicaciones infecciosas subsiguientes a la cirugía y/o procedimientos. Finalmente, el riesgo de la maniobra profiláctica antibiótica es la aparición de reacciones adversas (fundamentalmente alérgicas) y la selección de resistencias.

\section{Población bacteriana diana}

La población bacteriana diana depende de la localización de la complicación infecciosa a cubrir. Así las infecciones locales tras procedimientos odontogénicos son habitualmente polimicrobianas, ya que muchas de las especies aisladas suelen ir en parejas (Bacteroides sp. y Fusobacterium; Peptostreptococcus sp. y Prevotella sp.; Prevotella sp. y Eubacterium sp.), ${ }^{10,11}$ con un fuerte componente aerobio/anaerobio, ${ }^{12-14}$ y en mucho menor grado, microaerófilo, como corresponde a la posible contaminación/infección en el acto quirúrgico por microbiota normal de la boca y saliva, así como por odontopatógenos de enfermedad periodontal, que presenta una prevalencia muy elevada (el 50\% de la población adulta presenta gingivitis y el $30 \%$ periodontitis). ${ }^{15}$

Las infecciones sistémicas a prevenir en pacientes con enfermedad de base son las subsiguientes a la bacteriemia post-manipulación dental, que se produce generalmente tras procedimientos invasivos. Esta bacteriemia es en general monomicrobiana, y se origina por la contaminación/infección por microbiota normal u odontopatógenos en el acto quirúrgico. Se sabe desde los años 30 que, tras manipulaciones dentales, el número de hemocultivos positivos a bacterias del género Streptococcus es del 75\% en individuos con caries, gingivitis y periodontitis versus un $30 \%$ en sujetos sanos. ${ }^{16,17}$ tion by certain microorganisms (splenectomized patients and infection by capsulated bacteria of the Streptococcus or Haemophilus genera), or in patients with a generalized disorder of their immune system that facilitates septicemia (immunodepressed, immunocompromised and malnourished patients). Generally, the first step tends to be bacteremia that is produced after an invasive procedure. Bacteremia has been well studied as periodontal disease (periodontitis) is very prevalent, due to the permeability of the epithelium that surrounds the tooth-tissue interface, and to the levels of prostaglandin in local circulation that increases the number of leukocytes and levels of fibrinogen, slowing down circulation in these cases, which favors the passage of bacteria into the blood. ${ }^{7}$ Thus, in animal models, bacterial endocarditis is $48 \%$ in rats with periodontal disease versus $6 \%$ in healthy rats. ${ }^{8}$ In humans, bacteremia following invasive procedures is around $51-55 \% .{ }^{9}$

\section{Cost-benefit balance}

The physician's criteria for choosing antibiotic prophylaxis or not should be based on a cost benefit-risk concept. The economic cost of prophylactic treatment (which is usually of short duration) is satisfactory when compared to the total cost of the dental treatment. Evidently, the benefit is that infectious complications following surgery and/or procedures are prevented as a result of the antibiotic. Finally, the risk of the prophylactic antibiotic treatment is the appearance of adverse reactions (principally allergic) and the selection of resistances.

\section{Targeted bacterial population}

The targeted bacterial population depends on the location of the infectious complication that has to be covered. Thus, local infections after odontogenic procedures are usually polymicrobial, as many of the isolated species tend to occur in pairs (Bacteroides sp. and Fusobacterium; sp.; Peptostreptococcus sp. and Prevotella sp.; Prevotella sp. and Eubacterium $s p . ;), 10,11$ with a strong aerobic/anaerobic component, ${ }^{12-14}$ and to a lesser extent, microaerophile, as corresponds to the possible contamination/infection during the surgical procedure by normal microbiota of the mouth and saliva, as well as by odonto-pathogens of periodontal disease, which has a very high prevalence (50\% of the adult population has gingivitis and 30\% periodontitis). ${ }^{15}$

The systemic infections that should be prevented in patients with underlying disease are those that occur after post-dental manipulation bacteremia, which generally arises after invasive procedures. This bacteremia is generally monomicrobial, and it starts because of contamination/infection by normal microbiota or odonto-pathogens during the surgical procedure. It has been known since the 30's that, after dental work, the number of positive blood cultures of bacteria of the genus Streptococcus is $75 \%$ in individuals with caries, gingivitis and periodontitis versus $30 \%$ in healthy individuals. ${ }^{16,17}$

The microorganisms most frequently involved are the Streptococcus of the viridans group, followed by the coagu- 
Los microorganismos más frecuentemente involucrados son Streptococcus del grupo viridans, seguidos de especies coagulasa negativo (epidermidis) y coagulasa positivo (aureus, y quizá lugdunensis) del género Staphylococcus de origen oral, y por último en un 4-7\% de casos, bacilos gram negativos grupo HACEK (Haemophilus, Actinobacillus, Cardiobacterium, Eikenella, Kingella), varios de ellos considerados como odontopatógenos. ${ }^{19}$ No debe olvidarse la detección de bacteriemias por anaerobios (Eubacterium, Peptostreptococcus, Propionibacterium, Lactobacillus) en un porcentaje alto cuando se utilizan los métodos adecuados (hemocultivos para anaerobios). ${ }^{20,21}$ En la tabla 1 se muestran los patógenos odontógenos más frecuentes.

\section{Régimen de administración del antibiótico}

El principal objetivo de la profilaxis antibiótica es alcanzar niveles elevados de antibiótico en el suero durante el proceso quirúrgico, y durante unas horas más tras el cierre de la incisión. En este sentido la dosis empleada debe ser alta, nunca inferior a la usada como tratamiento. La administración previa a la intervención quirúrgica o procedimiento puede ser suficiente en la mayoría de las intervenciones. Sólo en aquellos casos en los que la vida media del antibiótico es inferior a una hora y la duración de la intervención de 2-3 horas, o más de dos veces la vida media del antibiótico, sería necesario repetir dosis. De forma similar si se produjese una pérdida sanguinea superior a 1-2 I durante el procedimiento, debería considerarse la administración de una dosis adicional de antibiótico. ${ }^{22-25}$

\section{Estado de salud del paciente}

Los procedimientos buco-dentales invasivos (anestesias locales intraligamentarias, procedimientos endodóncicos, curetajes, sondajes, extracción dentaria simple y compleja, trasplantes/reimplantes y cirugía periapical, periodontal, ósea, implantológica, de las mucosas así como biopsia de glándulas salivales, etc.) son aquellos que conllevan riesgo de infección en sujetos sanos en algunos casos y siempre en individuos con riesgo de infección local y/o general (sujetos transplantados, con injertos, inmunodeprimidos, desnutridos, con patología asociada no controlada, etc).2,26

Los procedimientos buco-dentales no invasivos (aplicación de fluor o sellado de fisuras, cuidados protésicos no sangrantes, retirada post-quirúrgica de suturas, ortodoncia, radiología y anestesia no intraligamentaria), no presentan riesgo de infección ni en sujetos sanos ni en sujetos con riesgo y por tanto nunca son candidatos a profilaxis antibiótica. 2,26 lase-negative species (epidermidis) and coagulase-positive (aureus, and perhaps lugdunensis) of the genus Staphylococcus with an oral origin. ${ }^{18}$ Lastly in 4 $7 \%$ of cases, are Gram-negative bacilli of the HACEK group (Haemophilus, Actinobacillus, Cardiobacterium, Eikenella, Kingella), several of which are considered odontopathogens. ${ }^{19}$ Nor should we forget the high percentage rate of bacteremias that are detected by anaerobes (Eubacterium, Peptostreptococcus, Propionibacterium, Lactobacillus) when adequate methods are used (blood cultures for anaerobes).20,21 Table 1 shows the most frequent odontogenic pathogens.

\section{Antibiotic administration regime}

The principal objective of antibiotic prophylaxis is to reach high serum levels of antibiotic during the surgical process, and for a few more hours after the incision is closed. In this sense the dose used should be high, and it should never be lower than that used as treatment. The amount administrated before the surgical intervention or procedure may be sufficient for most interventions. Only in those cases in which the half-life of the antibiotic is less than an hour and the duration of the intervention 2-3 hours, or more than twice the half-life of the antibiotic, will repeating the dose be necessary. Similarly, if there is blood loss of over 1-2 L during the procedure, the administration of an additional dose of antibiotics should be considered.22-25

\section{Patient's state of health}

Invasive oral/dental procedures (intraligamental local anesthesia, endodontic procedures, curettage, catheterization, simple and complex dental extractions, transplants/reimplants and periapical, periodontal, bone, implant or mucosal surgery, as well as biopsies of salivary glands, etc.) are those that entail a risk of infection in healthy individuals in some cases, and in individuals at risk for local and/or general infection (individuals with transplants or grafts, those 
En el caso de sujetos con riesgo de infección sistémica (sujetos con riesgo de endocarditis y portadores de prótesis articulares) estará indicada la profilaxis para procedimientos invasivos, siendo verdadera profilaxis preoperatoria (no cabiendo en este caso el concepto de tratamiento preventivo), 2,26 y generalmente en monodosis. En estos últimos casos es donde más se discute sobre implicaciones médico-legales, habiéndose producido litigios por ausencia de profilaxis o por la administración de antibióticos incorrectos o a tiempos incorrectos en la prevención de la endocarditis bacteriana. ${ }^{27}$

\section{Efectos no deseables (económicos, biológicos-resistencias, médicos-alérgicos)}

Por la acción exclusiva de los antibióticos sobre estructuras bacterianas los efectos adversos no son frecuentes cuando se comparan con otro tipo de fármacos.

En general la incidencia de efectos adversos de los antibióticos o las reacciones idiosincrásicas a los mismos son poco frecuentes. Esto permite que por en ejemplo en situaciones como la profilaxis de endocarditis bacteriana en pacientes sin historia de alergia a la penicilina se puedan utilizar dosis única de amoxicilina $2 \mathrm{~g}$ sin temor a encontrar reacciones anafilácticas. 28

La selección de resistencias en flora normal (faríngea o intestinal) depende del tipo de antibiótico utilizado, ya que la capacidad de selección de resistencias en la misma es distinta para cada compuesto, ${ }^{29,30}$ y menor con pautas cortas a dosis altas de profilaxis o tratamiento. ${ }^{31}$

\section{Toma de decisiones (empirismo ecuacional)}

En última instancia la decisión de profilaxis es potestativa del facultativo que atenderá a la ecuación: riesgo = daño $\times$ probabilidad de sufrirlo. Este enfoque es subjetivo, Ante la probabilidad, aunque sea remota, de daños irreparables, la prevención de complicaciones infecciosas sistémicas (p. ej. endocarditis infecciosa, infección tardía de prótesis articular) debe percibirse como importante por parte de los especialistas que las tratan (cardiólogos, traumatólogos, infectólogos, etc.). La prevención de complicaciones locales (p. ej. periimplantitis) como resultado de maniobras odontológicas quedará a criterio del especialista que la realiza, dada la escasez de ensayos clínicos adecuados.

\section{Fundamentos clínicos}

La aparición de una solución de continuidad en la piel, mucosa o tejidos duros de la boca como consecuencia del trauma quirúrgico o procedimental, conlleva la alteración de la principal barrera que frena la invasión de microorganismos. De esta manera los patógenos entran y pueden colonizar e infectar los tejidos profundos. Esto hace que, dependiendo del inóculo bacteriano, aumente la posibilidad de infección según sea un procedimiento o cirugía limpia, limpia-contaminada, contaminada o sucia. A mayor contaminación, mayor es el riesgo de infección postquirúrgica.

El riesgo de contaminación del campo quirúrgico se incrementa con el tiempo de exposición y la complejidad de la solución de who are immunodepressed, undernourished, or who have an uncontrolled associated pathology, etc.).2,26

Non-invasive oral/dental procedures (application of fluoride or sealing of fissures, bloodless prosthetic care, postsurgical suture removal, orthodontia, radiology and nonintraligamentary anesthesia) do not carry any risk of infection either in healthy individuals or in those at risk, and they are therefore never candidates for antibiotic prophylaxis. 2,26

In cases where there is a risk of systemic infection (individuals with a risk of endocarditis and those with joint prostheses), prophylaxis is indicated for invasive procedures, with this being true preoperative prophylaxis (and in this case the concept of preventative treatment is not included $)^{2,26}$ and generally it will be given in a single dose. These latter cases are the most debated with regard to medico-legal implications, and there have been litigation cases because of an absence of prophylaxis, or because antibiotics have been incorrectly administered, or there has been incorrect timing in the prevention of bacterial endocarditis. ${ }^{27}$

Undesirable effects (economical, biological-resistances, medical-allergic).

Because of the exclusive action of antibiotics on bacterial structures, adverse effects do not occur regularly when compared with other types of drugs.

In general there are very few incidences of adverse effects of antibiotics, or of idiosyncratic reactions to them. For example, in situations requiring prophylaxis such as bacterial endocarditis, in patients with no history of penicillin allergy, single doses of amoxicillin $2 \mathrm{~g}$ can be used without fear of encountering anaphylactic reaction. 28

Resistance selection in normal flora (pharyngeal or intestinal) depends on the type of antibiotic used, as the resistance selection capacity is different for each compound, 29,30 and lower when there are short courses of high-dose prophylaxis or treatment. ${ }^{31}$

\section{Decision-making (equational empiricism)}

In the last instance, the decision for prophylaxis depends on the physician and it will be based on the equation: risk $=$ damage $\mathrm{x}$ probability of suffering it. This is a subjective approach. If there is a probability, though it might be remote, of irreparable damage, the prevention of systemic infectious complications (for example infective endocarditis, late-onset of joint prosthesis infection) should be seen as important by the specialists treating them (cardiologists, traumatologists, infectologists, etc.). The prevention of local complications (for example peri-implantitis) as a result of odontogenic manipulation will be left to the criteria of the specialist performing the work, given the lack of adequate clinical trials.

\section{Clinical bases}

The appearance of a break in the skin, mucosa or hard tissues of the mouth as a consequence of surgical or procedural trauma, leads to the alteration of the principal barrier that stops the invasion of micro-organisms. Pathogens 
continuidad producida, y se minimiza con una adecuada técnica quirúrgica y con el buen estado del paciente. Pero el que se ha demostrado como factor más crítico y sujeto a debate es la profilaxis antibiótica.

Las medidas de control en la técnica quirúrgica para minimizar el riesgo de infección son: incisiones limpias; levantamientos mucoperiósticos libres de desgarros; irrigaciones como método de enfriamiento y arrastre de partículas de los fresados del hueso alveolar; aspiración constante y hemostasia cuidadosa. En caso de utilizar anestesia local, hay que evitar posibles desgarros tisulares con la aguja y asegurarse de la administración lenta del anestésico. Asimismo se debe tener precaución esmerada con separadores, retractores y depresor lingual en labios, colgajos y tejidos. Si fuera preciso la colocación de drenajes y apósitos compresivos se realizará en la posición adecuada. Finalmente, debemos recordar que algunas de las suturas efectuadas son puntos de aproximación, por lo que existe un tránsito tanto del ambiente húmedo propio de la cavidad bucal, como de residuos alimenticios, por lo que se recomienda hacer enjuagues con antisépticos o suero fisiológico a partir de las 24 horas siguientes a la intervención quirúrgica.

Como norma general, la profilaxis está indicada siempre que exista un riesgo importante de infección, ya sea por las características mismas de la operación o por las condiciones locales o generales del paciente. Entre los factores que van a determinar la posibilidad de aparición de infección destacan el tipo y tiempo de cirugía así como el riesgo quirúrgico del paciente por su comorbilidad (valorable en términos de riesgo anestésico o clase ASA): diabetes, nefropatías, hepatopatías (cirrosis), cardiopatías y terapéuticas inmunosupresoras (corticoides, radioterapia, quimioterapia, infecciones previas con antibioticoterapia no bien conocida o racionalizada). Las intervenciones menores en pacientes sanos en general no requieren profilaxis.

\section{¿Qué tipo de pacientes requieren profilaxis antibiótica?}

La utilización o no de profilaxis antibiótica en los procedimientos y técnicas quirúrgicas odontológicas dependerá del tipo de paciente y del tipo de procedimiento que se lleve a cabo. Determinados pacientes son candidatos a profilaxis en procedimientos invasivos. Por el contrario, los procedimientos no invasivos no requieren profilaxis en ningún caso.

A tal fín, los pacientes podrían clasificarse en: a) pacientes sanos, b) pacientes con factores de riesgo de infección local o sistémica y c) pacientes con factores de riesgo de infección focal tras bacteriemia.

En el sujeto sano la profilaxis se basa exclusivamente en el riesgo del procedimiento, ${ }^{26}$ presentando alto riesgo los trasplantes, reimplantes, injertos, cirugía tumoral y ósea (al igual que en cirugía ortopédica y traumatológica), así como la cirugía periapical y las inclusiones dentarias donde, además, es frecuente que coexista una infección previa. ${ }^{2,26}$

Los pacientes con factores de riesgo de infección local o sistémica son aquellos que presentan un aumento de susceptibilidad general a las infecciones. Son pacientes oncológicos, pacientes con inmunodepresión congénita o inmunológica (por ejemplo, lupus eritematoso), pacientes con inmunodepresión medicamentosa (corticoterapia, quimioterapia) tras trasplante, injerto o cualquier otra causa, pacientes con will enter in this manner, and they may colonize and infect deep tissues. Depending on the bacterial inoculum, the possibility of infection will increase depending on if the procedure or surgery has been clean, clean-contaminated, contaminated or dirty. The greater the contamination, the greater the risk of postsurgical infection.

The risk of contamination in the surgical field increases with exposure time and the complexity of the break that is produced, and it is minimized when the surgical techniques are appropriate and when the patient is in good health. But, what has been demonstrated to be the most critical and debated factor is antibiotic prophylaxis.

The measures that are taken with the surgical technique to minimize the risk of infection are: clean incisions; tear-free mucoperiosteal examinations; irrigation as a cooling method, and removing particles after alveolar bone drilling; constant aspiration and careful hemostasis. If local anesthesia is used, any possible tearing with the needle should be avoided and the anesthesia should be administered slowly. Likewise, great care should be taken with the separators, retractors and tongue depressors on the lips, flaps and tissue. Should placing drains and dressings be necessary, these should be placed in the proper position. Finally, we should remember that some of the suturing carried out is to bring the sides together and therefore humidity from the oral cavity itself can be transferred as well as food residues. Rinses with antiseptics or saline solution 24 hours after the surgical intervention are advisable.

As a general rule, prophylaxis is always indicated if there is a considerable risk of infection, either because of the characteristics of the operation itself or because of the local or general conditions of the patient. Among the factors standing out that determine the possibility of an infection appearing are the type and duration of the surgery as well as the surgical risk of the patient due to comorbidity (that can be evaluated in terms of anesthetic risk or ASA classification): diabetes, nephropathies, hepatopathies (cirrhosis), cardiopathies and therapeutic immunosuppressants (corticoids, radiotherapy, chemotherapy, previous infections with antibiotic therapy that is not well-known or not rationalized). Minor interventions in generally healthy patients do not require prophylaxis.

\section{What patient-type requires antibiotic prophylaxis?}

The use or not of antibiotic prophylaxis in surgical odontological techniques and procedures depends on the type of patient and the type of procedure that is carried out. Certain patients are candidates for prophylaxis in invasive procedures. On the other hand, non-invasive procedures never require prophylaxis.

Patients can therefore be classified into a) healthy patients, b) patients with local or systemic infection risk factors and c) patients with focal infection risk factors following bacteremia. 
inmunodepresión infecciosa (síndrome de inmunodeficiencia adquirida), pacientes con trastornos metabólicos (diabetes) y pacientes con insuficiencia renal o hepática. ${ }^{26}$ Además, están los pacientes esplenectomizados donde existe un mayor riesgo de infecciones por los géneros Streptococcus y Haemophilus. 32,33

Los pacientes con factores de riesgo de infección focal tras bacteriemia son aquellos que presentan riesgo de endocarditis infecciosa o de infección de prótesis osteoarticulares. Con respecto a la endocarditis infecciosa, el $14-20 \%$ de las mismas tienen un origen oral.9,34 Los antibióticos, aparte de reducir la prevalencia y magnitud de la bacteriemia, 9,35 (nunca llegan a eliminarla por completo), impiden la adherencia bacteriana al endocardio, ${ }^{36}$ lo que pudiera ser el mecanismo último de eficacia profiláctica. Las condiciones patológicas asociadas a riesgo de endocarditis infecciosa han sido definidas por la American Heart Association (AHA) en Estados Unidos, la British Society of Antimicrobial Chemotherapy (BSAC) en el Reino Unido y la Agence Française de Sécurité Sanitaire des Produits de Santé (Afssaps), 2,37,38 entre otros. Con respecto a las infecciones de prótesis osteoarticulares, la elección de la profilaxis antibiótica del procedimiento dental se basaría en su morbilidad ${ }^{39}$ devastadora y alta mortalidad, y no en la baja prevalencia de la asociación de estas infecciones con procedimientos dentales. ${ }^{32} \mathrm{~A}$ pesar de esta baja prevalencia, la profilaxis está indicada en prótesis implantadas hace menos de 2 años o cuando haya existido una infección de prótesis previa. ${ }^{2}$

En la tabla 2 se señalan los pacientes considerados de riesgo.

\section{¿Qué procedimientos odontológicos requieren profilaxis antibiótica?}

Ante estos hechos es necesario diferenciar entre procedimientos buco-dentales invasivos, aquellos susceptibles de producir un sangrado significativo (Tabla 3), y los no invasivos, aquellos que no son susceptibles de producir un sangrado significativo. Generalmente, los procedimientos invasivos pueden ser considerados de alto riesgo en pacientes frágiles.

Las heridas quirúrgicas fueron clasificadas por Altemeier de acuerdo con su riesgo potencial de contaminación e infección, en una
In the healthy individual, prophylaxis is based exclusively on the risk of the procedure, ${ }^{26}$ with transplants, re-implants, grafts, tumor and bone surgery being high-risk (just as in orthopedic and trauma surgery) as well as periapical surgery and embedded teeth where, in addition, there is frequently a previous coexisting infection. ${ }^{2,26}$

Patients with local or systemic infection risk factors are those that have general increased susceptibility to infections. These are oncological patients, patients that have a congenital or immunological immunodepression (for example lupus erythematous), patients with immunodepression because of medication (corticotherapy, chemotherapy) following a transplant, graft or any other reason and patients with an infectious immunodepression (acquired immunodeficiency syndrome), patients with metabolic disorders (diabetes) and patients with renal or hepatic insufficiency. ${ }^{26}$ There are also splenectomized patients where there is a higher risk of infection by the Streptococcus and Haemophilus genres. ${ }^{32,33}$

Patients with focal infection risk factors following bacteremia are those that have a risk of infective endocarditis or of bone and prosthetic joint infection. With regard to infective endocarditis, $14-20 \%$ of these cases have an oral origin.9,34 Antibiotics, in addition to reducing the prevalence and magnitude of bacteremia9,35 (they never completely manage to eliminate it completely), prevent bacterial adherence to the endocardium, ${ }^{36}$ which could be the ultimate mechanism for prophylactic efficiency. The pathologic conditions associated with the risk of infective endocarditis have been defined by the American Heart Association (AHA) in the United States, by the British Society of Antimicrobial Chemotherapy (BSAC) in the United Kingdom and by the Agence Française de Sécurité Sanitaire des Produits de Santé (Afss- 
clasificación, 40 que el tiempo ha consagrado por su utilidad práctica:

- Tipo I. Heridas limpias (no apertura de mucosas como la cavidad oral): Tasa verificada de infección de 1 a 4\%. No precisan profilaxis antibiótica.

- Tipo II. Heridas limpias-contaminadas (apertura de mucosas como la cavidad oral, inserción de implantes dentales o intervención por patología inflamatoria): Tasa verificada de infección de 5 a 15\%. Requieren profilaxis antibiótica con fármacos que cubran microorganimos grampositivos y anaerobios.

- Tipo III. Heridas contaminadas (patología oncológica en la que se actúa simultáneamente sobre la cavidad oral y el cuello): Tasa verificada de infección de 16 a 25\%. Debe efectuarse profilaxis antibiótica cubriendo gramnegativos, cuya cobertura es controvertida en cirugías limpias y limpias contaminadas.

- Tipo IV. Heridas sucias e infectadas: Tasa verificada de infección superior al $26 \%$. Precisan de un tratamiento antibiótico adecuado siempre.

Son candidatos a profilaxis en pacientes con factores de riesgo para infección local o sistémica (pacientes con factores de inmunodepresión), todos los procedimientos invasivos citados en la tabla 3.

En los pacientes con factores de riesgo de infección focal tras bacteriemia (endocarditis, infección de prótesis) está siempre indicada la profilaxis de los procedimientos invasivos que puedan realizarse en este tipo de pacientes.

En el sujeto sano la profilaxis sólo está recomendada en caso de exodoncia de diente incluido, cirugía periapical, cirugía ósea, cirugía implantaria, injertos óseos y cirugía de tumores benignos.
Tabla 3. Procedimientos invasivos y su riesgo

$\begin{array}{ll}\text { Procedimiento } & \text { Riesgo } \\ \text { Utilización de grapas para aislamiento absoluto con } & \text { Bajo riesgo } \\ \text { dique de goma } & \\ \text { Profilaxis periodontal e implantaria } & \text { Bajo riesgo } \\ \text { Sondaje periodontal } & \text { Bajo riesgo } \\ \text { Mantenimiento periodontal } & \text { Bajo riesgo } \\ \text { Aanestesia intraligamentosa } & \text { Alto riesgo } \\ \text { Técnicas de anestesia troncular } & \text { Bajo riesgo } \\ \text { Extracciones } & \text { Alto riesgo } \\ \text { Reimplantes dentarios (Intencionales y Traumáticos) } & \text { Alto riesgo } \\ \text { Biopsias } & \text { Alto riesgo } \\ \text { Incisiones para drenajes } & \text { Alto riesgo } \\ \text { Injertos oseos } & \text { Alto riesgo } \\ \text { Aplicación y retirada de suturas quirúrgicas } & \text { Bajo riesgo } \\ \text { Raspado y alisado radicular } & \text { Alto riesgo } \\ \text { Cirugía periodontal } & \text { Alto riesgo } \\ \text { Cirugía de inserción de implantes } & \text { Alto riesgo } \\ \text { Cirugía mucogingival } & \text { Alto riesgo } \\ \text { Remoción de pilares de implantes } & \text { Bajo riesgo } \\ \text { Endodoncia } & \text { Bajo riesgo } \\ \text { Cirugía endodóntica apicectomía } & \text { Alto riesgo } \\ \text { Procedimientos y colocación de bandas de ortodoncia } & \text { Bajo riesgo } \\ \text { Colocación de aparatos de ortodoncia removibles } & \text { Bajo riesgo } \\ \text { Toma de impresiones } & \text { Bajo riesgo } \\ \text { Colocación de hilo retractor } & \text { Bajo riesgo } \\ \text { Procedimientos de tallado que incluyan sangrado } & \text { Alto riesgo } \\ \text { Cirugía preprotésica } & \text { Alto riesgo } \\ \text { Cirugía ortognática } & \text { Alto riesgo } \\ \text { Reducción de fracturas maxilares } & \text { Alto riesgo } \\ \text { Cirugía de las glándulas salivales } & \text { Alto riesgo } \\ \text { Cirugía oncológica maxilofacial } & \text { Alto riesgo }\end{array}$

Table 3. Invasive procedures and risk

\section{Procedure}

Use of staples for total isolation with rubber dam

Implant and periodontal prophylaxis

Periodontal probing

Periodontal maintenance

Intraligamental anesthesia

Trunk anesthesia techniques

Extractions

Dental reimplants (Intentional y Traumatic)

Biopsies

Incisions for drains

Bone grafts

Application and removal of surgical sutures

Scaling and root planing

Periodontal surgery

Implant insertion surgery

Mucogingival surgery

Removal of implant abutment

Endodontia

Endodontic surgery and apicectomy

Orthodontic procedures and placement of bands

Placement of removable orthodontic appliances

Taking of impressions

Placing of retractor cord

Filing procedures that include bleeding

Preprosthetic surgery

Orthognathic surgery

Reduction of maxillary fractures

Salivary gland surgery

Oncologhical maxillofacial surgery aps), 2,37,38 among others. With regard to bone and prosthetic joint infection, the choice of antibiotic prophylaxis in dental procedures is based on the devastating morbidity and high mortality, ${ }^{39}$ and not on the association of these infections with dental procedures ${ }^{32}$ being low. Despite this low prevalence, prophylaxis is indicated for prostheses that have been implanted at least two years previously or where there has been a previous infection of the prosthesis. ${ }^{2}$

Table 2 shows the patients that are considered at risk.

What dental procedures require antibiotic prophylaxis?

In view of these facts, one has to differentiate between invasive oral-dental procedures, those that are likely to produce significant bleeding (Table 3), and noninvasive procedures, those that are not likely to produce significant bleeding. Generally, invasive procedures can be considered high-risk in fragile patients.

Altemeier classified surgical wounds according to the potential risk of contamination and infection40 that time has confirmed as being of practical utility: 


\section{Criterios de selección: diana bacteriana, flora normal, aspectos farmacocinéticos y farmacodinámicos y selección del antibiótico adecuado}

\section{El antibiótico y la diana bacteriana de la profilaxis}

Las bacterias que causan las infecciones odontogénicas son generalmente saprofitas. Durante la evolución de la caries dental, las bacterias que penetran en los túbulos dentinarios son fundamentalmente anaerobios facultativos como Streptococcus spp, Staphylococcus spp y lactobacilos. Cuando la pulpa se necrosa, las bacterias avanzan por el conducto radicular y el proceso evoluciona hacia una inflamación periapical. En esta fase predominan Prevotella spp, Porphyromonas spp, Fusobacterium spp y Peptostreptococos spp. La microbiología de las complicaciones infecciosas es variada, existen múltiples combinaciones de todos estos organismos, con diferentes características, pero tanto las bacterias anaerobias como las aerobias están presentes habitualmente.

Frente a los bacilos gram positivos aerobios o facultativos implicados (Eubacterium, Actinomyces y Propionibacterium) y espiroquetas, todos los grupos de antibióticos habitualmente utilizados (aminopenicilinas, amoxicilina + ac. clavulánico, macrólidos, lincosamidas y metronidazol) son activos excepto el metronidazol. Frente a cocos gram positivos implicados (Streptococcus, Staphylococcus y Peptostreptococcus) sólo la amoxicilina + ac. clavulánico presenta una cobertura adecuada. ${ }^{2}$ Frente a Veillonella, todos son activos excepto los macrólidos (eritromicina, claritromicina y azitromicina). Frente a los bacilos gram negativos implicados (Prevotella, Porphyromonas, Fusobacterium, Selenomonas, Eikenella, Capnocytophaga, Actinobacillus, Campylobacter rectus y Tanerella forsytensis), amoxicilina + ac. clavulánico y clindamicina presentan una cobertura adecuada (excepto para Eikenella corrodens en el caso de la lincosamida). La alta prevalencia de producción de $\beta$-lactamasa en la flora anaerobia oral normal o patológica hace que la amoxicilina sin inhibidor de $\beta$-lactamasa (ác. clavulánico) no sea un antibiótico adecuado desde el punto de vista fisiopatológico. En la tabla 4 se resume la actividad de los principales antibióticos frente a los patógenos odontógenos más frecuentes.

\section{El antibiótico y la flora normal}

El régimen antibiótico adecuado será aquel que más selectivamente actúe sobre las bacterias que pueden producir complicaciones, respetando al máximo la flora saprofita habitual.

Es importante considerar el aspecto ecológico a la hora de elegir el régimen antibiótico a utilizar. Se debe elegir el antibiótico y el régimen posológico (este factor con menos importancia si el curso profiláctico es corto o de dosis única) que menos altere la flora saprófita normal. Tomando Escherichia coli como índice de flora intestinal, los macrólidos y cetólidos son respetuosos ya que este microorganismo es resistente a estos compuestos. Las quinolonas, sin embargo, han seleccionado un alto grado de resistencias, ${ }^{42}$ pero estos compuestos no están indicados en odontología. Mientras la amoxicilina ha seleccionado altas tasas de resistencias a $E$. coli por producción de $\beta$-lactamasa, la sensibilidad de la amoxicilina unida al ác. clavulánico es muy alta. Donde se ha estudiado más extensivamente la flora normal es en nasofaringe tomando como bacte-
- Type I. Clean wounds (no mucosal opening such as the oral cavity): Established rate of infection of 1-4\%. Antibiotic prophylaxis is not needed.

- Type II. Clean-contaminated wounds (mucosal opening such as the oral cavity or inflammatory pathology intervention): Established rate of infection 5 to 15\%. Antibiotic prophylaxis is required with drugs covering Grampositive and anaerobic micro-organisms.

- Type III. Contaminated wounds (oncological pathology in which the oral cavity and neck are acted on simultaneous(y): Established infection rate of 16 to 25\%. Antibiotic prophylaxis should be carried out to cover Gramnegative organisms. This coverage for clean and cleancontaminated surgery is controversial.

- Type IV. Dirty and infected wounds: Established rate of infection above $26 \%$. Adequate antibiotic treatment is always necessary.

All the invasive procedures that appear in Table 3 require prophylaxis in patients with risk factors for local or systemic infection (patients with immunodepression factors).

In patients with risk factors for focal infection after bacteremia (endocarditis, prosthetic infection) prophylaxis is always indicated for invasive procedures that may be carried out in these types of patients.

For healthy individuals prophylaxis is only recommended if an embedded tooth is extracted, for periapical surgery, bone surgery, implant surgery, bone grafts and benign tumor surgery.

Selection criteria: bacterial target, normal flora, pharmacokinetic and pharmacodynamic aspects and selection of the appropriate antibiotic

Antibiotics and the bacterial target of the prophylaxis

The bacteria that cause odontogenic infections are generally saprophytes. During the development of dental caries, the bacteria penetrating the dentin tubules are fundamentally facultative anaerobes such as Streptococcus spp, Staphylococcus spp and lactobacilli. When there is pulp necrosis, the bacteria advance along the root canal and the process evolves towards periapical inflammation. Predominating this phase are Prevotella spp. Porphyromonas spp, Fusobacterium spp and Peptostreptococci spp. The microbiology of infectious complications is varied, there are multiple combinations of all these organisms, with different characteristics, but both anaerobic as well as aerobic bacteria are habitually present.

Against aerobic or facultative Gram-positive bacilli involved (Eubacterium, Actinomyces and Propionibacterium) and spirochetes, all the antibiotic groups that are usually used (aminopenicillins, amoxicillin + clavulanic acid, macrolides, lincosamides and metronidazole) are active except metronidazole. Against the Gram-positive cocci involved 
Tabla 4. Actividad de varios antimicrobianos frente a periodontopatógenos

\begin{tabular}{|c|c|c|c|c|c|c|}
\hline $\begin{array}{r}\text { Acti } \\
\text { actinomy }\end{array}$ & $\begin{array}{l}\text { Aa } \\
\text { obacillus } \\
\text { etemcomitams }\end{array}$ & $\begin{array}{l}\text { Peptostreptococcus } \\
\text { spp }\end{array}$ & $\begin{array}{l}\text { Prevotella } \\
\text { spp }\end{array}$ & $\begin{array}{l}\text { Porphyromonas } \\
\text { spp }\end{array}$ & $\begin{array}{l}\text { Fusobacterium } \\
\text { spp }\end{array}$ & $\begin{array}{l}\text { Estreptococos } \\
\text { orales }\end{array}$ \\
\hline Penicilina G & \pm & + & \pm & \pm & + & + \\
\hline Amoxicilina & + & + & \pm & \pm & + & + \\
\hline Amoxicilina/a. clavulánico & + & + & + & + & + & + \\
\hline Doxiciclina & + & \pm & \pm & \pm & + & + \\
\hline Clindamicina & $\mathrm{O}$ & + & + & + & + & + \\
\hline Metronidazol & $\mathrm{O}$ & + & + & + & + & $\mathrm{O}$ \\
\hline Macrólidos & \pm & \pm & \pm & \pm & \pm & + \\
\hline
\end{tabular}

Table 4. Activity of various antimicrobials on periodontal pathogens

\begin{tabular}{|c|c|c|c|c|c|c|}
\hline $\begin{array}{r}A c \\
\text { actinom }\end{array}$ & $\begin{array}{l}\text { Aa } \\
\text { obacillus } \\
\text { etemcomitams }\end{array}$ & $\begin{array}{l}\text { Peptostreptococcus } \\
\text { spp }\end{array}$ & $\begin{array}{l}\text { Prevotella } \\
\quad \text { spp }\end{array}$ & $\begin{array}{l}\text { Porphyromonas } \\
\text { spp }\end{array}$ & $\begin{array}{c}\text { Fusobacterium } \\
\text { spp }\end{array}$ & $\begin{array}{c}\text { Oral } \\
\text { Streptococci }\end{array}$ \\
\hline Penicillin G & \pm & + & \pm & \pm & + & + \\
\hline Amoxicillin & + & + & \pm & \pm & + & + \\
\hline Amoxicillin/clavulanic acid & + & + & + & + & + & + \\
\hline Doxycyline & + & \pm & \pm & \pm & + & + \\
\hline Clindamycin & 0 & + & + & + & + & + \\
\hline Metronidazole & 0 & + & + & + & + & 0 \\
\hline Macrolides & \pm & \pm & \pm & \pm & \pm & + \\
\hline
\end{tabular}

+ More than $80 \%$ strain sensitivity. O Less than $30 \%$ strain sensitivity. \pm Between $30-80 \%$ strain sensitivity.

ria índice Streptococcus pneumoniae, microorganismo del mismo género que otras especies que son aislamientos prevalentes en infecciones odontogénicas (grupo viridans). ${ }^{43}$

Con respecto a los estreptococos se ha relacionado el consumo de antibióticos como única causa con las resistencias en las especies $S$. pyogenes y S. pneumoniae, tanto desde un punto de vista temporal, 44,45 como geográfico, 46,47 estando las resistencias a macrólidos en estas dos especies ligadas a nivel local. 48 Mientras que la responsabilidad de las aminopenicilinas en la selección de resistencias en S. pneumoniae es baja, los fármacos que más resistencias a penicilina y macrólidos seleccionan en S. pneumoniae son las cefalosporinas orales de administración dos veces al día, pero no son fármacos de elección en odontología y sobre todo, los macrólidos de administración una o dos veces al día en S. pneumoniae y S. pyogenes. Estos hechos tienen traducción en las especies del grupo viridans del género Streptococcus donde la alta resistencia a macrólidos (eritromicina, claritromicina) ${ }^{49}$ se asocia frecuentemente a alta resistencia a tetraciclinas, ${ }^{50}$ y a clindamicina y azálidos (azitromicina). ${ }^{51}$ Considerando que el consumo de antibióticos en odontología supone el $10 \%$ del total del consumo de antibióticos en la comunidad, como se ha comentado, es posible sospechar un grado de responsabilidad no despreciable en la selección de resistencias por tratamientos antimicrobianos en odontología. Así en nuestro país se ha descrito una alta prevalencia de bacteriemias iatrogénicas orales causadas por estreptococos resistentes a eritromicina $(40,8 \%)$ y clindamicina $(21 \%)$, siendo la mayoría de los aislados sensibles a aminopenicilinas. 52
(Streptococcus, Staphylococcus and Peptostreptococcus) only amoxicillin + clavulanic acid present adequate cover. ${ }^{2}$ All are active against Veillonella except the macrolides (erythromycin, clarithromycin and azithromycin). Against the Gram-negative bacilli involved Prevotella, Porphyromonas, Fusobacterium, Selenomonas, Eikenella, Capnocytophage, Actinobacillus, Campylobacter rectus and Tanerella forsytensis), amoxycilin + clauvulanic acid and cilindamicin (except for Eikenella corrodens in the case of lincosamide). The high prevalence of B-lactamase production in normal or pathologic anaerobic flora means that amoxycillin without B-latamase inhibitor (clauvulanic acid) is not adequate from the physiopathologic point of view. Table 4 summarizes the activity of the principal antibiotics versus the most frequent odontogenic pathogens. ${ }^{41}$

\section{Antibiotics and normal flora}

A suitable antibiotic regime will be the one that acts most selectively on the bacteria that may produce complications, while respecting to the maximum the habitual saprophyte flora.

It is important to consider the ecological aspect when electing the antibiotic regime to be used. The antibiotic and the dose chosen (this factor is of less importance if the prophylactic course is short or if there is a single dose) should be the one that will least affect the normal saprophyte flora. If Escherichia coli is taken as an indicator of intestinal flora, macrolides and cetolides are respectful as this microorgan- 


\section{Aspectos farmacocinéticos farmacodinámicos}

Para algunos antibióticos, las concentraciones antibióticas en el fluido gingival son similares o superiores a las séricas, como se ha visto en el caso de amoxicilina + ác. clavulánico, 53,54 espiramicina, metronidazol, ${ }^{55}$ y quinolonas (fármacos no indicados en el campo odontológico en la actualidad). La cobertura farmacodinámica se entiende como el valor de la "relación entre los parámetros farmacocinéticos séricos y susceptibilidad in vitro" que predice eficacia: a) porcentaje del intervalo de dosificación en que los niveles de antibiótico superan la CMI (mínima concentración antibiótica que produce inhibición del crecimiento bacteriano in vitro) que debe ser superior al $40-50 \%$ para $\beta$ lactámicos, macrólidos y lincosamidas, y b) relación del área bajo la curva de los niveles séricos/CMl que debe ser superior a 25 para azálidos (azitromicina). Se han publicado trabajos que aplican estos conceptos en odontología, analizando distintos antibióticos frente a los cinco aislados más prevalentes (pero no frente a todas las bacterias implicadas) en infecciones odontogénicas (Streptococcus grupo viridans, Peptostreptococcus sp., Prevotella intermedia, Porphyromonas gingivalis y Fusobacterium nucleatum) ${ }^{43}$ Sólo amoxicilina + ac. clavulánico a dosis de $875 / 125$ mg cada 8 h o la nueva formulación de 2000/125 mg cada

$12 \mathrm{~h}$ así como la clindamicina $300 \mathrm{mg}$ cada 6-8h cumplen los requisitos farmacodinámicos. ${ }^{56,57}$ Sin embargo, la clindamicina ofrece una peor cobertura frente a estreptococos orales y Peptostreptococcus adecuadamente, presentando un nivel no despreciable de resistencias. El metronidazol no tiene actividad frente a bacterias aerobias y los macrólidos, incluyendo la espiramicina, tienen un elevado porcentaje de resistencias a los estreptococos orales y ofrecen una actividad muy limitada frente a Peptostreptococcus spp y Fusobacterium nucleatum.

En la tabla 5 se reflejan las posologías recomendadas para profilaxis de diferentes antibióticos.

\section{Selección del Antibiótico adecuado}

El antibiótico a elegir (en caso de considerar necesaria la profilaxis por el tipo de procedimiento y tipo de paciente) debe cumplir las siguientes características:
Tabla 5. Dosis iniciales pre-intervención recomendadas en profilaxis

\begin{tabular}{|c|c|c|}
\hline Antibiótico & Dosis Adultos & Dosis niños ${ }^{\dagger}$ \\
\hline Amoxicilina & $2 \mathrm{~g} \mathrm{VO}$ & 50 mg/Kg VO \\
\hline Ampicilina & $2 \mathrm{~g} \mathrm{IM} \circ \mathrm{IV}$ & $50 \mathrm{mg} / \mathrm{Kg}$ IM o IV \\
\hline Amoxicilina + & $2 \mathrm{~g}+125 \mathrm{mg}$ VO & $50+6,25 \mathrm{mg} / \mathrm{Kg}$ VO \\
\hline Ac. clavulánico & $2 \mathrm{~g}+200 \mathrm{mg} \mathrm{IV}$ & $50+5 \mathrm{mg} / \mathrm{Kg} \mathrm{IV}$ \\
\hline Cefazolina* & $1 \mathrm{~g} \mathrm{IM}$ o IV & $25 \mathrm{mg} / \mathrm{kg}$ IM o IV \\
\hline Cefalexina o cefadroxil ${ }^{*}$ & $2 \mathrm{~g} \mathrm{VO}$ & 50 mg/Kg VO \\
\hline Clindamicina & $\begin{array}{l}600 \mathrm{mg} \text { VO } \\
600 \mathrm{mg} \text { IV }\end{array}$ & $\begin{array}{c}20 \mathrm{mg} / \mathrm{Kg} \text { VO } \\
15 \mathrm{mg} / \mathrm{Kg} \mathrm{IV}\end{array}$ \\
\hline Claritromicina y azitromicina & 500 mg VO & $15 \mathrm{mg} / \mathrm{kg}$ VO \\
\hline Gentamicina & $\begin{array}{l}1,5 \mathrm{mg} / \mathrm{Kg} \mathrm{IV} \\
\text { exceder de } 120 \mathrm{mg})\end{array}$ & $1,5 \mathrm{mg} / \mathrm{kg} \mathrm{IV}$ \\
\hline Metronidazol & $1 \mathrm{~g} \mathrm{IV}$ & $15 \mathrm{mg} / \mathrm{kg} \mathrm{IV}$ \\
\hline Vancomicina & $1 \mathrm{~g} \mathrm{IV}$ & $20 \mathrm{mg} / \mathrm{Kg}$ IV \\
\hline
\end{tabular}

dosis total en niños no debería superar la dosis de adultos; Dosis de segui位ad de la dosis inicial; " Las cefalosporinas no deberían utilizarse en ientes con reacción de hipersensibilidad tipo I a la penicilina (urticaria,

Table 5. Initial pre-intervention doses recommended in prophylaxis

\begin{tabular}{|c|c|c|}
\hline Antibiotic & Adult dose & Pediatric dose ${ }^{\dagger}$ \\
\hline Amoxicillin & $2 g P O$ & $50 \mathrm{mg} / \mathrm{Kg} \mathrm{PO}$ \\
\hline Ampicillin & $2 g I M$ or IV & $50 \mathrm{mg} / \mathrm{Kg}$ IM or IV \\
\hline Amoxicillin + Clavulanic A. & $2 g+125 m g P O$ & $50+6,25 \mathrm{mg} / \mathrm{Kg} P O$ \\
\hline & $2 g+200 \mathrm{mg} I V$ & $50+5 \mathrm{mg} / \mathrm{Kg} \mathrm{IV}$ \\
\hline Cefazolin* & $1 \mathrm{~g} I \mathrm{M}$ or IV & $25 \mathrm{mg} / \mathrm{kg} \mathrm{IM}$ or IV \\
\hline Cephalexine or cephadroxil* & $2 g P O$ & $50 \mathrm{mg} / \mathrm{Kg} \mathrm{PO}$ \\
\hline \multirow[t]{2}{*}{ Clindamycin } & $600 \mathrm{mg} P O$ & $20 \mathrm{mg} / \mathrm{Kg} P O$ \\
\hline & $600 \mathrm{mg} \mathrm{IV}$ & $15 \mathrm{mg} / \mathrm{Kg} \mathrm{IV}$ \\
\hline $\begin{array}{l}\text { Clarithromycin and } \\
\text { azithromycin }\end{array}$ & $500 \mathrm{mg} P O$ & $15 \mathrm{mg} / \mathrm{kg}$ PO \\
\hline Gentamicin & $\begin{array}{c}1,5 \mathrm{mg} / \mathrm{Kg} \mathrm{IV} \\
\text { (no more than } 120 \mathrm{mg} \text { ) }\end{array}$ & $1,5 \mathrm{mg} / \mathrm{kg} \mathrm{IV}$ \\
\hline $\begin{array}{l}\text { Metronidazole } \\
\text { Vancomycin1 g IV }\end{array}$ & $\begin{array}{c}1 \mathrm{~g} / \mathrm{V} \\
20 \mathrm{mg} / \mathrm{Kg} \mathrm{IV}\end{array}$ & $15 \mathrm{mg} / \mathrm{kg} \mathrm{IV}$ \\
\hline
\end{tabular}

†The total pediatric dose should not surpass the adult dose; follow-up dose should be half the initial dose; *Cephalosporins should not be used in patients with Type I hypersensitivity to penicillin (rash, angioedema or anaphylaxis).

PO: per os; IM: intramuscular; IV: intravenous. ism is resistant to these compounds. Quinolones, however, have selected a high degree of resistance ${ }^{42}$ but these compounds are not indicated in dentistry. While amoxicillin has selected high rates of resistance to $E$. coli because of b-lactamase production, the sensibility of amoxicillin together with clavulanic acid is very high. Normal flora has been studied more extensively in the nasopharynx with Streptococcus pneumoniae as the index bacteria, a microorganism of the same genus as other species that are prevalent isolates in dental infections (viridans group). ${ }^{43}$ With regard to Streptococci, the consumption of antibiotics has been linked as the sole cause of resistance in the species S. pyogenes and S. pneumoniae, from a time t4,45 $^{4}$ well as geographical46,47 point of view. Resistance to macrolides in both these species is linked at a local level.48 While the responsibility of aminopenicillins in the selection of resistances in S. pneumoniae is low, the drugs that select the most resistance to penicillin and macrolides in S. pneumoniae are oral cephalosporins that are administered twice a day, but these are not drugs of choice in dentistry, and particularly macrolides that are administered once or twice a day in S. pneumoniae and S. pyogenes. These facts can be seen in the species of the viridans group of the genus Streptococcus where the high resistance to macrolides (erythromycin, clarithromycin) 49 is associated frequently with high resistance to tetracyclins ${ }^{50}$ and to clindamycin and azalides (azithromycin). ${ }^{51}$ Considering that the consumption of antibiotics in dentistry involves $10 \%$ of the total consumption of antibiotics in the community, as previously mentioned, 
1. Espectro bacteriano adecuado, cubriendo todas las especies involucradas en las infecciones polimicrobianas locales o monomicrobianas focales distales, incluyendo microorganismos aerobios, microaerófilos, sin olvidar los anaerobios que debido a la dificultad en su aislamiento en ocasiones no son considerados prevalentes en bacteriemias de origen oral.

2. Espectro clínico amplio, para cubrir el mayor número de procedimientos odontológicos

3. Espectro ecológico restringido para limitar al máximo los efectos sobre la flora saprófita habitual.

4. Farmacocinética y farmacodinamia adecuadas, para permitir su utilización en monodosis pre-operatoria en el caso de la profilaxis, o intervalos de dosificación amplios en el tratamiento preventivo de corta duración, con vidas medias o formulaciones de liberación prolongada que mantengan concentraciones adecuadas a nivel local (fluido gingival) o sistémico (suero) durante todo el tiempo que dure el procedimiento odontológico (profilaxis).

5. Perfil de seguridad adecuado, incluso en población infantil y tercera edad.

Los antibióticos administrados oralmente que son efectivos ante infecciones odontogénicas incluyen penicilina, clindamicina, eritromicina, cefadroxilo, metronidazol y las tetraciclinas. Penicilina $V$ fue la penicilina de elección ante infecciones odontogénicas. Es bactericida, y aunque su espectro de acción, es relativamente estrecho, era el apropiado para los tratamientos de infecciones odontogénicas. Para la profilaxis de endocarditis asociada con tratamientos dentales, la amoxicilina es el antibiótico de primera elección. ${ }^{37}$ La amoxicilina más el ácido clavulánico es en la actualidad el fármaco de elección de este grupo al presentar la gran ventaja de conservar su actividad contra las b-lactamasas producidas comúnmente por microorganismos que se asocian con infecciones odontogénicas.

Una alternativa, en casos de pacientes alérgicos a las penicilinas, es la clindamicina. Es bacteriostático, pero su actividad bactericida se consigue clínicamente con la dosis generalmente recomendada. Los últimos macrólidos, claritromicina y azitromicina pueden ser usados también, si el paciente es alérgico a la penicilina. Metronidazol se suele usar sólo contra anaerobios y se suele reservar para situaciones en las que sólo se sospeche de bacterias anaerobias. Las tetraciclinas tienen un uso muy limitado en la odontología. Como las tetraciclinas pueden causar alteraciones en el color de los dientes, no se deben prescribir en niños menores de 8 años, mujeres embarazadas o madres lactantes.

\section{Valor de los antisépticos e higiene bucodental.}

El uso de antisépticos tópicos en la cavidad oral reduce el inóculo bacteriano, pero no ha demostrado ser eficaz en la profilaxis de la colonización bacteriana. No obstante, el uso de antisépticos preoperatorios en la cavidad oral puede reducir las complicaciones derivadas del trauma en la mucosa, especialmente en pacientes con valvulopatías, implantes de material aloplástico, injertos óseos, inmunodeprimidos, ancianos y en pacientes con mala higiene oral. the degree of responsibility in resistance selection due to dental antimicrobial treatment should not be underestimated. Thus, a high prevalence of iatrogenic oral bacteremias has been described in our country caused by Streptococci resistant to erythromycin (40.8\%) and clindamycin (21\%), with most of the isolates being sensitive to aminopenicilins. ${ }^{52}$

\section{Pharmacokinetic and pharmacodynamic aspects}

With some antibiotics, the antibiotic concentration in gingival fluid is similar or superior to the serum concentrations, as has been seen in the cases of amoxicillin and clavulanic acid, ${ }^{53,54}$ spiramycin, metronidazole $e^{55}$ and quinolones (drugs that are currently not recommended in the dental field). Pharmacodynamic coverage is understood as the value of the "relationship between the serous pharmacokinetic parameters and in vitro susceptibility" that predicts efficacy: a) percentage of the dose interval at which the antibiotic levels surpass the MIC (minimum antibiotic concentration that produces inhibition of bacterial growth in vitro) that should be above $40-50 \%$ for $\beta$-lactamics, macrolides and lincosamides, and b) relationship of the area under the curve of the serum levels/MIC that must be above 25 for azalides (azithromycin). Papers have been published that apply these concepts in dentistry, and which analyze the different antibiotics and compare these with the five most prevalent isolates (but not with all the bacteria involved) in dental infections. (Streptococcus Viridans group, Peptostreptococcus sp., Prevotella intermedia, Porphyromonas gingivalis and Fusobacterium nucleatum. 43 Only amoxicillin and clavulanic acid at a dose of $875 / 125 \mathrm{mg}$ every 8 hours or the new formula of 2000/125 mg every 12 hours, as well as clindamycin $300 \mathrm{mg}$ every 6-8h, comply with pharmacodynamic requirements. $43,56,57$ However, clindamycin offers worse coverage for oral Streptococci and adequate for Peptostreptococcus, while the level of resistance should not be underestimated. Metronidazole is not active against aerobic bacteria, and macrolides including spiramycin, have a high percentage of resistance to oral Streptococci and they offer very limited activity against Peptostreptococcus spp and Fusobacterium nucleatum.

Table 5 shows the recommended doses for prophylaxis of the different antibiotics.

Choosing the right antibiotic.

The antibiotic chosen (if prophylaxis is considered necessary because of the type of procedure and type of patient) should meet the following characteristics.

1. Suitable bacterial spectrum covering the species involved in local polymicrobial infections or distal focal monomicrobial infections, including aerobic microorganisms, microaerophiles, not forgetting anerobes that given the difficulty in isolating them, are sometimes not considered prevalent in bacteremias of oral origin.

2. Ample clinical spectrum for covering the greatest number of dental procedures.

3. Restricted ecological spectrum in order to limit to the maximum the effects of the usual saprophyte flora. 


\section{Análisis de la patología dentaria}

La caries es una enfermedad multifactorial, en la que interviene, entre otros factores, una microbiota muy variada, las bacterias mas frecuentes son los estreptococos del grupo mutans, seguidas del género de Lactobacillus. Estas bacterias intervienen en la formación de la placa bacteriana, pero con una composición diferente según la localización. ${ }^{58,59}$

La penetración bacteriana del diente se produce sin necesidad de una solución de continuidad en la superficie externa, produciéndose fundamentalmente a través de las laminillas o craks, los pits y las áreas intervarillas del esmalte, incluso en dientes normales sin caries. En casos de caries de esmalte incipiente no cavitada, se puede observar la invasión bacteriana en las capas mas profundas del esmalte, alcanzando el límite amelo dentinario e incluso en las capas profundas de la dentina, ${ }^{60,61}$ donde se detectan, en los estadios iniciales de la caries dentinaria, fundamentalmente Lactobacillus, siendo colonizado posteriormente por Streptococcus y Actinomyces spp.

Los estreptococos del grupo mutans (S. mutans, S. sobrinus, $S$. cricetus, S. ratius, S. ferus, S. downwi y S. macacae), ${ }^{62}$ son los mas importantes en la etiopatogenia de la caries, por lo que la prescripción de una tratamiento antibacteriano, en pacientes de alto riesgo que aún no tengan lesión evidente, es aconsejable de modo profiláctico. ${ }^{63}$ Se utiliza clorhexidina, fluoruros tópicos y antibióticos del tipo de la vancomicina (bloquea la síntesis de la pared bacteriana), la kanamicina y actinomicina (bloque la síntesis proteica) así como soluciones halogenadas a base de yodo y flúor. ${ }^{63}$

El número de bacterias que invaden la pulpa o los tejidos periapicales es directamente proporcional al grado de extensión de las vías de penetración. La invasión bacteriana de la pulpa condiciona siempre una respuesta inflamatoria pulpar y la gravedad del proceso que se desarrolla va a depender de una serie de factores como son : el carácter de la invasión, la microbiota, el número de microorganismos, las endotoxinas, las exoenzimas, los metabolitos, las exotoxinas, el tiempo de actuación y la capacidad defensiva del hospedador. ${ }^{64}$

Las bacterias que contaminan el tejido pulpar, pueden invadir asimismo los tejidos periapicales, pero el grado de invasión bacteriana depende no sólo de la capacidad de multiplicarse, sino también, de la motilidad de las bacterias. ${ }^{64}$

La mayoría de las bacterias que originan patología periapical son sensibles, en orden de efectividad, al tratamiento con amoxicilina/ácido clavulánico, ampicilina/sulbactam, Clindamicina, metronidazol, macrólidos, penicilinas (ampicilinas, amoxicilinas).

Uno de los grandes problemas del fracaso endodontico es debido a la persistencia de la invasión bacteriana a nivel del conducto o del periápice, por causas muy diversas, habiéndose aislado preferentemente dos especies bacterianas: Actinomyces israelii, ${ }^{5}$ y Enterococcus faecalis. ${ }^{66}$ Se ha observado resistencia de Actinomyces israelli, ${ }^{67}$ a metronidazol y de Enterococcus faecalis a clindamicina. ${ }^{6}$

\section{Análisis de la patología quirúrgica bucal y maxilofacial}

Los datos de la literatura son contradictorios, si bien las series parecen indicar que la reducción de las complicaciones postopera-
4. Suitable pharmacokinetics and pharmacodynamics, to allow the use of single pre-operative doses in the case of prophylaxis, or extended dosing intervals for short-term preventative treatment, with half-lives or extended-release formulas that maintain adequate concentrations locally (gingival fluid) or systemically (serum) during the total duration of the dental procedure (prophylaxis).

5. Suitable safety profile that includes children and the elderly. The antibiotics that are administered orally that are effective for dental infections include penicillin, clindamycin, erythromycin, cefadroxil, metronidazole and tetracyclines. These antibiotics are effective against streptococci and oral anaerobes. Penicillin $V$ was the penicillin of choice for odontogenic infections. It is a bactericide, and although its action spectrum is relatively narrow, it was appropriate for the treatment of odontogenic infections. For prophylaxis of endocarditis associated with dental treatment, amoxicillin is the first-choice antibiotic. ${ }^{37}$ Amoxicillin with clavulanic acid is currently the drug of choice for this group as it has the great advantage of conserving its activity against the $\beta$-lactamases commonly produced by micro-organisms that are associated with odontogenic infections.

An alternative in the case of patients that are allergic to penicillins is clindamycin. It is bacteriostatic, but its bactericidal activity is achieved clinically with the generally recommended dose. The latest macrolides, clarithromycin and azithromycin can also be used if the patient is allergic to penicillin. Cefadroxil cephalosporin can be used when a wider antibacterial spectrum of action is needed. Metronidazole can be used only against anaerobes and it tends to be reserved for situations in which only anaerobic bacteria are suspected. Tetracyclines are of very limited use in dentistry. As tetracyclines can cause changes in the color of teeth they should not be prescribed for children under the age of 8 , or for women that are pregnant or breast-feeding.

Value of antiseptics and oral/dental hygiene

The use of topical antiseptics in the oral cavity reduces the bacterial inoculate, but they have not been proved effective in the prophylaxis of bacterial colonization. Nevertheless, the use of preoperative antiseptics in the oral cavity can reduce the complications derived from mucosal trauma especially in patients with valvulopathies, implants of alloplastic material, bone grafts, immunodepressed or elderly patients, and patients with bad oral hygiene.

\section{Analysis of dental pathology}

Caries is a multifactorial disease involving, among other factors, very varied microbiota. The most common bacteria are the streptococci of the mutans group, followed by the genus Lactobacillus. These bacteria are involved in the formation of bacterial plaque, but with a different composition depending on their location. 58,59 
torias se debe tanto a la mejora en la técnica quirúrgica como a un uso racional de la profilaxis antibiótica. En términos generales, se recomienda la antibioterapia per y postoperatoria en aquellos casos en que haya alto riesgo de infección o signos clínicos evidentes de infección.

Las intervenciones quirúrgicas pueden ser clasificadas en dos grandes grupos, atendiendo a la presencia de gérmenes o no en la zona de la intervención. Enumeramos a continuación una serie de operaciones tipo de la especialidad:

1. Intervenciones quirúrgicas sin presencia de gérmenes: dientes retenidos; exostosis, torus; tumores odontogénicos, quistes (no infectados); épulis, cirugía preprotésica y preortodóntica; fracturas maxilares (cerradas); afección glandular; osteotomías; injertos, colgajos y otros.

2. Intervenciones quirúrgicas con presencia de gérmenes: pericoronaritis del tercer molar, quistes inflamatorios, restos radiculares, granulomas, etcétera; sialolitiasis, fracturas abiertas, traumatismos, heridas contusas; sobreinfección añadida a la lesión tumoral, radionecrosis y otros.

\section{Cirugía oral}

La tasa de infección es baja, por lo que en pacientes sanos la mayoría de procedimientos en cirugía oral no requieren antibioterapia. Se empleará tratamiento antibiótico profiláctico en casos de infección activa, pacientes con comorbilidad o inmunocomprometidos.

Exodoncia de cordales. Algunas series parecen demostrar que el uso de antibioterapia postoperatoria no mejora el pronóstico frente a la posibilidad de infección postoperatoria. ${ }^{69,70}$ Sin embargo, una parte de autores recomiendan el uso de la profilaxis basándose en el descenso significativo de complicaciones posquirúrgicas como el dolor, el trismus, el retraso en la cicatrización de la herida y la tumefacción. ${ }^{71-74}$ En un reciente ensayo clínico aleatorizado, doble ciego, de grupos paralelos se comparó la eficacia de la antibioterapia pre y postoperatoria con placebo. En el estudio se aleatorizó a los pacientes en tres grupos: Grupo placebo, grupo de profilaxis preoperatorio (amoxicilina/ácido clavulánico 2000/125 mg en una sola dosis antes de la cirugía) y grupo de profilaxis postoperatoria o tratamiento preventivo (amoxicilina/ácido clavulánico 2000/125 mg cada 12h durante 5 días comenzando dentro de las 3 horas después de la cirugía). La prevalencia de infección postquirúrgica fue significativamente mayor $(P=0,006)$ en el grupo de pacientes tratado con placebo (16\%) que en el grupo de pacientes que recibió amoxicilina/ácido clavulánico 2000/125 mg, bien como profilaxis preoperatoria $(5,3 \%)$, bien como profilaxis postoperatoria (2,7\%). En las intervenciones que precisaron osteotomía, el tratamiento preventivo fue mejor que la profilaxis preoperatorio y el placebo $\left(24,9\right.$ y $4 \%$, respectivamente). ${ }^{3}$

Implantología. Conceptualmente encuadradada dentro de las heridas tipo II, una reciente revisión de la literatura sobre la eficacia de los antibióticos en la prevención de complicaciones y fracasos tras la realización de implantes dentales concluyó que no hay evidencia ni para recomendar ni para desaconsejar el uso de antibióticos para la prevención de complicaciones y fracasos de implantes dentales, debido a la ausencia de ensayos clínicos aleatorizados y controlados. ${ }^{75}$
Bacterial penetration of the tooth is produced without any need for an opening in the external surface. It is produced fundamentally through the chips or cracks, pits and the point of contact of the enamel, even in normal teeth without caries. In cases of incipient enamel caries without cavities, bacterial invasion can be observed in the deeper layers of the enamel, reaching the enamel/dentine border* and even the deeper dentine layers, ${ }^{66,61}$ where Lactobacillus is mainly detected during the initial stages of dental caries, with later colonization by Streptococci and Actinomyces spp.

Mutans group streptococci (S. mutans, S. sobrinus, $S$. cricetus, S. ratius, S. ferus, S. downwi and S. macacae)62 are the most important in the etiopathogeny of caries, and the prescription of antibacterial treatment in high-risk patients that have yet to develop an obvious lesion is advisable for prophylactic purposes. ${ }^{63}$ Chlorhexidine, topical fluoride and antibiotics of the vancomycin type are used (bacterial wall synthesis is blocked), kanamycin and actinomycin (protein synthesis is blocked) as well as halogenated solutions with an iodine and fluoride base. ${ }^{63}$

The number of bacteria that invade the pulp or periapical tissues is directly proportional to the degree of extension of the penetration paths. Bacterial invasion of the pulp always conditions an inflammatory response in the pulp, and how serious the process will become will depend on a series of factors such as: the nature of the invasion, the microbiota, the number of micro-organisms, the endotoxins, the exoenzymes, the metabolites, the exotoxins, the acting time and the defensive capacity of the host. ${ }^{64}$

The bacteria that contaminate pulp tissue, can also invade periapical tissue, but the degree of bacterial invasion depends not only on its ability to multiply but also on the motility of the bacteria. ${ }^{64}$

Most bacteria that originate periapical pathology are sensitive, in order of effectiveness, to treatment with amoxicillin/clavulanic acid, ampicillin/sulbactam, clindamycin, metronidazole, macrolides, penicillins (ampicillins, amoxicillins).

One of the great problems of endodontic failure is due to persistent bacterial invasion of the canal or periapical region, as a result of very diverse reasons, and two bacterial species have preferably been isolated: Actinomyces israelii65 and Enterococcus faecalis. ${ }^{66}$ Resistance has been observed in Actinomyces israelli67 to metronidazole and in Enterococcus faecalis to clindamycin. ${ }^{6}$

\section{Analysis of oral and maxillofacial surgical pathology}

The data in the literature are contradictory, although the series appear to indicate that the reduction in postoperative complications is due as much to an improvement in surgical techniques as to the rational use of antibiotic prophylaxis. In general terms, peri- and post-operative antibiotic therapy is recommended for those cases where there is a high risk of infection or obvious clinical signs of infection. 
Gynther y cols., compararon la eficacia de penicilina $\mathrm{V}$ administrada antes y después de la intervención frente a placebo 279 pacientes, no encontrando diferencias en lo referido a tasa de infección postoperatoria o supervivencia del implante entre los dos grupos. ${ }^{76}$ Dent y cols., en un estudio multicéntrico en 2641 implantes dentales encontraron una significativa menor tasa de fracasos en aquellos que habían recibido antibióticos preoperatorios en comparación con aquéllos que no habían recibido. Finalmente, en un estudio reciente no se observó mayor eficacia con el uso de antibioterapia postoperatoria durante 7 días frente a dosis única intraoperatoria. ${ }^{77}$ En pacientes con radioterapia previa se emplean regímenes prolongados de antibioterapia para evitar la presencia de osteomielitis o pérdida de los dispositivos de implantes osteointegrados. Igualmente, basándonos en la experiencia clínica, en pacientes con inmunodeficiencias, enfermedades metabólicas (como diabetes), pacientes con factores de riesgo de endocarditis, la utilización de antibióticos estaría recomendada.

\section{Traumatología}

Está ampliamente aceptado el uso de antibioterapia profiláctica en fracturas complejas o múltiples.

Fracturas de mandíbula y dentoalveolares. Los esquemas de tratamiento antibiótico son los clásicos del resto de la patología cervicofacial (penicilina y derivados y cefalosporinas de tercera generación). El tratamiento profiláctico antibiótico en las fracturas no complicadas no parece aportar beneficios si bien muchos profesionales tratan estas fracturas para cubrir las posibles infecciones para reducir su incidencia. El tratamiento antibiótico en las primeras 72 horas no resulta necesario. El tratamiento antibiótico de las complicaciones infecciosas (abscesos, pseudoartrosis, osteomielitis, etc.) es donde mayor consenso existe, si bien en este caso ya deja de ser antibioterapia profiláctica para convertirse en terapéutica.

Fracturas orbitarias. No hay consenso en la literatura (algunos autores abogan por el tratamiento antibiótico mientras que otros no).

Fracturas de tercio medio y superior. Se emplean cefalosporinas de tercera generación, en aquellos casos en que se presente licuorrea.

\section{Cirugía ortognática y cirugía preprotésica}

Se consideran cirugías limpias-contaminadas, en las cuales algunas series han demostrado la efectividad de la profilaxis antibiótica postoperatoria (penicilina, cefalosporinas que no mejoran el pronóstico y suponen un mayor coste), si bien otros autores parecen demostrar que no hay evidencias de mejor pronóstico frente a infección por el uso de antibioterapia postoperatoria, especialmente si se administra vía oral.

Se ha descrito una mayor incidencia de infecciones en cirugía bimaxilar sin tratamiento antibiótico.

Algunos estudios han utilizado levofloxacino oral o cefazolina iv en osteotomías mandibulares, pero en el caso de ésta última, es mejor utilizar amoxicilina-clavulánico por cepas resistentes a cefazolina.

El tiempo de tratamiento se había establecido en publicaciones previas en 5 días para cobertura antibiótica profiláctica, pero la inci-
Surgical interventions can be classified into two large groups depending on the presence of germs or not in the intervention region. We will now list a series of standard operations of the specialty.

1. Surgery without the presence of germs: embedded teeth; exostosis, torus; odontogenic tumors, cysts (uninfected); epulis, pre-prosthetic and pre-orthodontic surgery; maxillary fractures (closed); glandular affection; osteotomies; grafts, flaps and others.

2. Surgical interventions with the presence of germs: pericoronaritis of the third molar, inflammatory cysts, root remains, granulomas, etc.; sialolitiasis, open fractures, trauma, wounds with contusions; additional infection of tumor lesions, radionecrosis and others.

\section{Oral surgery}

The infection rate is low, and therefore, in healthy patients most oral surgery procedures do not require antibiotherapy. Prophylactic antibiotic treatment will be used in cases of active infection, patients with co-morbidity or who are immunocompromised.

Exodontia of wisdom teeth: Some series appear to demonstrate that the use of post-operative antibiotherapy does not improve prognosis in relation to the possibility of postoperative infection. 69,70 However, there are some authors who recommend the use of prophylaxis based on the significant reduction of post-operative complications such as pain, trismus, delays in the healing of wounds and swelling. ${ }^{71-74}$ In a recent randomized, double-blind clinical trial with parallel groups, the efficacy of pre- and post-antibiotic therapy was compared with a placebo. In the study, the patients were randomized into three groups: placebo group, preoperative prophylaxis group, (amoxicillin/clavulanic acid 2000/125 $\mathrm{mg}$ in a single dose before the surgery) and the group of postoperative prophylaxis or preventative treatment (amoxicillin/clavulanic acid 2000/125 mg every 12 h for 5 days within the first three hours after surgery). The prevalence of postsurgical infection was significantly greater $(P=0.006)$ in the patients treated with placebos (16\%) than in the group of patients that were given amoxicillin/clavulanic acid $2000 / 125 \mathrm{mg}$, either as preoperative prophylaxis (5.3\%) or as postoperative prophylaxis (2.7\%). In the interventions that required osteotomies, preventative treatment was better than preoperative prophylaxis and the placebo (24\%, $9 \%$ and $4 \%$ respectively). ${ }^{3}$

Implantology. A recent review of the literature on antibiotic efficacy in preventing complications and failures after carrying out dental implants, concluded that there was no evidence for either recommending or for discouraging the use of antibiotics for the prevention of complications and failures of dental implants, due to the absence of randomized and controlled clinical trials. 75

Gynther and cols. compared the efficacy of penicillin $V$ administered before and after the intervention with a placebo in 279 patients. They did not find any differences with 
dencia de infección postoperatoria es igual en regímenes de 1 ó 5 días, si bien hay cierta mejoría en la morbilidad postoperatoria prolongando el tratamiento durante 5 días.

\section{Glándulas salivales}

En cirugías como parotidectomía o submaxilectomía se ha demostrado la ausencia de efectividad del uso de profilaxis antibiótica.

\section{Cirugía oncológica, reconstructiva y cervical}

Se ha demostrado que el uso de antibióticos perioperatorios reduce significativamente la incidencia de infecciones postoperatorias. Como en los casos anteriores, en patología cervical y, fundamentalmente, en cirugía oncológica, se pueden utilizar regímenes de antibioterapia profiláctica combinando clindamicina y cefazolina, cefalosporinas, aminoglucósidos, quinolonas o derivados de la penicilina con inhibidores de betalactamasas.

El riesgo de infección surge ante la posibilidad de poner en contacto áreas limpias con la mucosa oral, puesto que la principal fuente de contaminación en estos pacientes es la saliva que transporta una cantidad importante de bacterias. Otros factores contribuyentes son el mal estado general, los estados de inmunosupresión, radioterapia o quimioterapia preoperatoria, colgajos de reconstrucción o aquellos procedimientos que expongan a los tejidos a isquemia o necrosis tisular. Las fuentes de microorganismos en estas patologías son la saliva, la piel, dientes y el propio tumor, por lo que el antibiótico a elegir debe cubrir no sólamente a los microorganismos comunes de la saliva, como cocos grampositivos y anaerobios, sino también a gramnegativos que se aíslan comúnmente en los tumores. Gran parte de las referencias en la literatura no consideran que haya que cubrir los microorganismos gramnegativos en cirugía oncológica de cabeza y cuello, pero recientes publicaciones si parecen asociar un mejor pronóstico con cobertura de gramnegativos.

Una pauta de antibioterapia puede ser gentamicina + clindamicina, que cubren bien grampositivos, gramnegativos y anaerobios (no así la cefazolina que no cubre anaerobios). También amoxicilina-clavulánico y ampicilina-sulbactam tienen el mismo espectro, frente a la clindamicina que no cubre suficientemente a los anaerobios.

La duración del tratamiento no está estandarizada quedando en muchos casos a criterio del cirujano. La antibioterapia postoperatoria suele mantenerse hasta la retirada de los drenajes, si bien se prolonga en casos de infección de herida quirúrgica, dehiscencia o fístula.

\section{Análisis de la patología periodontal}

Aunque la mayor parte de los principios de la profilaxis antibiótica en periodoncia se basan en conceptos generalizables a la profilaxis por procedimientos bucales quirúrgicos, las infecciones periodontales presentan particularidades que es conveniente tratar de forma separada. regard to the rate of postoperative infection or implant survival between both groups. ${ }^{76}$ Dent and cols. in a multicentric study of 2641 dental implants found a significantly lower rate of failures in those that had received preoperative antibiotics compared with those that had not. Finally, in a recent study, greater efficacy was not observed when postoperative antibiotic therapy was used for seven days compared with a single intraoperative dose. ${ }^{77}$ In patients with prior radiotherapy, prolonged regimes of antibiotic therapy were used in order to avoid the presence of osteomyelitis or loss of the osseointegrated implant devices. Likewise, based on clinical experience, the use of antibiotics would be recommended for patients with immunodeficiencies, metabolic diseases (such as diabetes), and patients with risk factors for endocarditis.

\section{Traumatology}

The use of prophylactic antibiotic therapy is widely accepted for complex or multiple fractures.

Mandible and dentoalveolar fractures: antibiotic treatment guidelines are traditionally used in the remaining cervicofacial pathologies (penicillin and derivatives and third generation cephalosporins). Prophylactic antibiotic treatment for uncomplicated fractures does not appear to be of any benefit although many professionals treat these fractures in order to cover possible infections and reduce incidence rates. Antibiotic therapy during the first 72 hours is not necessary. Antibiotic treatment of infectious complications (abscesses, pseudoarthrosis, osteomyelitis...) is where most consensus exists, although in this cases, it is no longer prophylactic antibiotherapy as it becomes therapeutic.

Orbital fractures: there is no consensus in the literature (some authors defend antibiotic therapy while others do not).

Fractures of the upper and middle third: third generation cephalosporins are used for those cases with liquorrhea.

\section{Orthognathic and preprosthetic surgery}

These are considered clean-contaminated surgeries. Some series have demonstrated the effectiveness of postoperative prophylactic antibiotic surgery (penicillin, cephalosporins that do not improve prognosis and involve higher costs), although other authors appear to have demonstrated that there is no evidence of improved prognosis with regard to infection as a result of using postoperative antibiotherapy, especially if administered orally.

A greater incidence of infections in bimaxillary surgery without antibiotic therapy has been described.

Some studies have used oral levofloxaxin or cefazolin IV in mandibular osteotomies, but in this latter case, it is better to use amoxicillin-clavulanic acid as there are strains that are resistant to cefazolin.

In previous publications treatment time had been established at 5 days for prophylactic antibiotic coverage, but the incidence of postoperative infection is the same in regimes of 1 to 5 days, although there is certain improvement in post- 


\section{¿Qué procedimientos en Periodoncia requieren tratamiento profiláctico con antibioterapia?}

Esta pregunta podría formularse de otra manera: ¿qué procedimientos en periodoncia producen bacteriemias?

Todos los procedimientos dentales que inducen sangrado desarrollaran una bacteriemia que rara vez persistirá más de 15 minutos. ${ }^{78}$ Podrían considerarse que cumplen en Periodoncia estos criterios los siguientes procedimientos o técnicas:

Se ha observado que el sondaje periodontal en humanos causa una bacteriemia transitoria, confirmada mediante hemocultivos. . $9,80^{2}$ Asimismo estudios en animales han puesto de manifiesto que las técnicas de raspado y alisado radicular pueden causarla. ${ }^{81}$ En humanos se ha observado que las técnicas de raspado y alisado radicular causan un bacteriemia transitoria, independientemente de que éstas se realicen mediante instrumentación con curetas o que se utilice instrumentación ultrasónica. ${ }^{82,83} \mathrm{La}$ aplicación de clorhexidina al 0,12\% mediante irrigación subgingival, inmediatamente o durante la instrumentación con aparatología ultrasónica o curetas, reduce pero no elimina la bacteriemia transitoria. ${ }^{82,83}$ La utilización de otros antisépticos como povidona yodada tras la instrumentación periodontal, no ha demostrado eficacia para reducir o eliminar la bacteriemia transitoria.

La cirugía periodontal causa una bacteriemia transitoria que se reduce de forma significativa con la utilización de profilaxis antibiótica. ${ }^{85}$ Aunque la utilización de antibioterapia en los procedimientos de cirugía periodontal es muy discutida, las infecciones postoperatorias se producen a pesar de que la prevalencia de éstas infecciones sea baja. ${ }^{86} \mathrm{Al}$ retirar las suturas se produce también una bacteriemia transitoria. ${ }^{87}$

La controversia podría producirse cuando se analiza la evidencia sobre bacteriemias producidas por maniobras no invasivas como el cepillado de dientes o mascar un chicle. ${ }^{88,89}$ En la tabla 6 se muestra la incidencia de bacteriemias comparando actuaciones de tratamiento dental y las maniobras de higiene bucal. 92,90

La cuestión que surge entonces es, si estímulos productores de bacteriemias se producen de forma espontánea varias veces al día sin ningún tipo de cobertura antibiótica, ¿otros procedimientos invasivos relacionados con manipulaciones quirúrgicas deberán realizarse bajo cobertura antibiótica?

Aunque se invoca que la extensión de la inflamación y la gravedad de la misma estarían relacionadas con la magnitud de la bacteriemia y es lógico pensar así, no se ha relacionado de forma experimental con el grado clínico-anatomopatológico de la inflamación.

Estudios histológicos han demostrado que, incluso en condiciones de normalidad clínica, está siempre presente una cierta alte-
Bacteriemia por higiene bucal

Cepillado de dientes $0-26 \%$

Uso de seda dental $20-58 \%$

Uso de palillos de dientes $20-40 \%$

Irrigación 7-50\%

Masticación 17-51\% operative morbidity by prolonging treatment for 5 days.

Salivary glands The lack of efficacy of antibiotic prophylaxis has been demonstrated in parotidectomy and sub-maxillectomy surgery.

Oncological, reconstructive and cervical surgery

It has been demonstrated that the use of perioperative antibiotics significantly reduces the incidence of postoperative infections. As in previous cases, cervical pathology and, fundamentally oncological surgery, prophylactic antibiotherapy regimes can be used combining clindamycin and cefazolin, cephalosporins, aminoglucosides, quinolones or penicillin derivatives with betalactamase inhibitors.

The risk of infection arises when there is a possibility of clean areas coming into contact with the oral mucosa, as the main source of contamination in these patients is from saliva that carries a considerable amount of bacteria. Other contributing factors are general bad health, a state of immunosuppression, radiotherapy or preoperative chemotherapy, reconstruction flaps or those procedures that expose tissues to ischemia or tissue necrosis. The sources of microorganisms in these pathologies are saliva, the skin, teeth and the tumor itself, and the antibiotic of choice has to cover not only common micro-organisms of the saliva, such as Grampositive and anaerobic cocci, but also those that are Gramnegative that are commonly isolated in tumors. Most of the references in the literature do not consider that Gram-negative micro-organisms have to be covered in oncological head and neck surgery, but recent publications do seem to associate better prognosis with Gram-negative coverage.

An antibiotic guideline could be gentamicin + clindamycin, that cover Gram-positive, Gram-negative and anaerobes well (but not cefazolin as it does not cover anaerobes). Amoxicillin-clavulanic acid and ampicillin-sulbactam also have the same spectrum, as opposed to clindamycin that does not cover anaerobes sufficiently.

The duration of treatment is not standardized and it in many cases it is left to the surgeon's judgment. Postoperative antibiotic therapy tends to be maintained until the drain has been removed, although this is extended in cases of infection of the surgical wound, dehiscence or fistula. 
ración tisular que sería compatible con un entorno favorable a las bacteriemias. ${ }^{93}$ Tampoco se ha establecido la diferencia entre gingivitis y periodontitis en la producción de bacteriemias. ${ }^{94}$

Además, por epidemiología conocemos que la mayor parte de la población en cualquier edad presenta ciertos niveles de inflamación clínica y la encía sana se encuentra en porcentajes muy bajos de población. ${ }^{95}$

\section{Análisis de la patología en edad infantil}

La profilaxis antibiótica en los niños sigue los mismos principios que para el adulto, teniendo en cuenta únicamente las peculiaridades de farmacocinética y toxicidad. En este sentido y a modo de ejemplo la utilización de algunos antibióticos como las quinolonas no están recomendadas en la edad infantil. Del mismo modo las tetraciclinas no deberían administrarse en menores de 8 años.

Como punto de partida, consideramos necesario realizar una serie de particularidades diferenciales del tratamiento antibiótico en el niño: a) El niño en sus primeras etapas carece de antecedentes médicos que hagan sospechar de la presencia de posibles cuadros de reacciones adversas o de alergia a los fármacos; b) La mayor proporción de agua en los tejidos del niño, además de la mayor esponjosidad de los tejidos óseos, permiten una más rápida difusión de la infección de un lado, y de otro, se hace necesario el ajuste adecuado de las dosis del medicamento prescrito; c) los procedimientos anestésicos en dientes temporales en proceso de rizolisis pueden incluir la realización de inyecciones intraligamentarias, que aumentan sin embargo, la posibilidad de bacteriemia; d) la deficiente higiene oral en la mayoría de los niños y el consumo de alimentos ricos en sacarosa, contribuyen a aumentar el número de colonias de gérmenes en la cavidad oral, y con ello el riesgo de bacteriemia tras los tratamientos orales; y e) Las resistencias a los antibióticos en los niños presentan una extraordinaria complejidad tanto por su elevada incidencia como por sus circunstancias asociadas. ${ }^{46,47}$

Varios estudios han evaluado la prevalencia y la extensión de bacteriemias después de diferentes procedimientos dentales en niños. Se demostró que sólo el cepillado está asociado con bacteriemia en más de uno de cada tres niños. ${ }^{96}$ Los tratamientos conservadores odontológicos, en los que se colocan cuñas o matrices, o en el caso de procedimientos ortodóncicos como la colocación o retirada de bandas, pueden originar bacteriemia en un número significativo de niños. ${ }^{97}$ En una extracción sencilla de un diente, aparece bacteriemia en un $40-50 \%$ de los niños examinados. ${ }^{96}$ Los niveles más altos de bacteriemia se encuentran tras las inyecciones intraligamentarias en procedimientos de anestesia local (96,6\% de los niños)..$^{98}$ En más del $50 \%$ de los casos se aislaron estreptococos del grupo viridans.

El nivel de higiene oral influye en los niveles de bacteriemia considerablemente. Por esta razón, una higiene oral óptima podría ser el factor más importante en la prevención de complicaciones como consecuencia de una bacteriemia; en opinión de algunos autores, más que cualquier pauta antibiótica. ${ }^{99}$

La patología traumática dentaria, constituye un factor etiológico de infección del área oral, máxime cuando se produce la expo-

\section{Analysis of periodontal pathology}

Although most of the principles in antibiotic prophylaxis in periodontics are based on concepts that can be generalized to prophylaxis for surgical oral procedures, periodontal infections should be singled out and dealt with separately.

\section{What Periodontal procedures require prophylactic} treatment with antibiotherapy?

This question could be put in another way: What procedures in periodontics produce bacteremias?

All dental procedures that induce bleeding develop bacteremia that will rarely persist for more than 15 minutes. ${ }^{78}$ It could be considered that the following procedures or techniques meet these criteria in Periodontics:

It has been observed that periodontal probing in humans causes transitory bacteremia, confirmed by blood cultures. $.9,80$ Studies in animals have shown that scaling and root planing can cause this. ${ }^{81}$ In humans it has been observed that scaling and root planing cause transitory bacteremia, independently of whether this has been carried out by means of curette or ultrasonic instrumentation. ${ }^{82,83}$ The application of chlorhexidine at $0.12 \%$ by means of subgingival irrigation, immediately or during instrumentation with ultrasonic apparatus or curettes, reduces but does not eliminate transitory bacteremia. ${ }^{82,83}$ The use of other antiseptics such as povidone iodine after the use of instrumentation in the periodontal area, has not been shown to be effective for reducing or eliminating transitory bacteremia. ${ }^{84}$

Periodontal surgery causes transitory bacteremia that is significantly reduced by the use of antibiotic prophylaxis. 85 Although the use of antibiotherapy in periodontal surgery procedures is much debated, postoperative infections arise despite the fact that the prevalence of these infections is low. ${ }^{86}$ Transitory bacteremia is also produced on removing the sutures. ${ }^{87}$ The controversy could occur when the evidence of bacteremias produced by non-invasive practices such as the brushing of teeth or the chewing of gum is analyzed. $.88,89$ Table 6 shows the incidence of bacteremias with regard to dental treatment actions and oral hygiene operations are compared. $90-92$

The question that arises is, if bacteremia producing stimuli occur spontaneously several times a day without any type of antibiotic coverage, should other invasive procedures related to surgical manipulation be carried out under antibiotic coverage?

Although it is said that the extent of the inflammation and its seriousness might be related to the magnitude of the bacteremia, and it would be logical to think this, it has not been connected in an experimental form with the clinicalanatomic-pathologic degree of the inflammation.

Histological studies have demonstrated that even under normal clinical conditions, there is always certain tissue disturbance that would be compatible with a favorable envi- 
sición directa del tejido pulpar, y/o alteración del espacio periodontal. Las posibilidades de infección aumentarán cuando al traumatismo en el tejido dental duro o de soporte, se le sume la presencia de heridas abiertas en piel o mucosas.

\section{Profilaxis de endocarditis bacteriana}

Estas recomendaciones son un resumen de los acuerdos y documentos de consenso de la Academia Americana de Cardiología, ${ }^{37}$ que ha sido aceptado con posterioridad por la mayoría de sociedades científicas y profesionales.

Se hará en todo paciente con cardiopatía predisponente que vaya a ser sometido a un procedimiento con riesgo de bacteriemia en cirugía oral y maxilofacial. En función del riesgo de endocarditis podemos clasificar las cardiopatías en: ${ }^{37}$

1. De alto riesgo. Prótesis endovascular, endocarditis previa, cardiopatía congénita cianógena compleja o fístulas sistémico-pulmonares realizadas quirúrgicamente.

2. De riesgo moderado. Otras cardiopatías congénitas, valvulopatías adquiridas, prolapso mitral con insuficiencia, miocardiopatía hipertrófica.

3. De bajo riesgo. CIA ostium secundum, CIA o CIV intervenidos, by-pass previo, prolapso mitral sin regurgitación, marcapasos, desfibrilador implantable.

Requieren profilaxis antibiótica los pacientes de alto riesgo y riesgo moderado que vayan a ser intervenidos en el ámbito maxilofacial usando como pautas antibióticas 1 hora antes vía oral o 30 minutos antes vía intravenosa. En la tabla 7 pueden verse los antibióticos recomendados en niños y adultos.

Adicionalmente, en los niños con historia de implementación de drogas intravenosas, y ciertos síndromes (ej. Down, Marfan), pueden tener riesgo de sufrir endocarditis bacteriana, por las anomalias cardiacas asociadas.

Aunque no esta sustentado en la evidencia científica, la Academia Americana de Cardiología recomienda que "los individuos con riesgo de desarrollar endocarditis bacteriana deben mantener la mejor higiene oral posible". Otros autores han llegado a afirmar que "mantener un buen estado de salud oral, que reduzca las bacteriemias diarias, es probablemente más importante a la hora de prevenir la endocarditis que la administración preventiva de antibióticos antes de intervenciones dentales concretas". Es preciso hacer énfasis, por tanto, en el mantenimiento de una buena salud periodontal como forma de prevención delas bacteriemias y por tanto del riesgo de endocarditis.

Otro aspecto que deberá ser aclarado en el futuro es si las bacteriemias asociadas a periodontitis activas se reducen de forma significativa con el control de la infección periodontal y por tanto, si el tratamiento es una forma de profilaxis eficaz contra la endocarditis. Las bacterias periodontopatógenas raramente causan endocarditis aunque el grupo de microorganismos denominado HACEK entre los que se encuentran Actinobacillus actinomycetemcomitans y Eikenella Corrodens ha aumentado su importancia en la etiología, lo que sustentaría la hipótesis de un aumento relativo del peso de las enfermedades periodontales en la etiología de las endocarditis. ronment for bacteremias. ${ }^{93}$ Nor has any difference been established between gingivitis and periodontitis in the production of bacteremias. ${ }^{94}$

Moreover, epidemology studies have shown that most of the population at whatever age has certain levels of clinical inflammation, and that healthy gums are to be found in a very low percentage of the population. 95

\section{Analysis of the pathology in children}

Antibiotic prophylaxis in children follows the same principles as in adults. Only the pharmacokinetic and toxicity peculiarities have to be taken into account. In this respect, and by way of example, the use of certain antibiotics such as quinolones is not recommended for children. Likewise, tetracyclines should not be administered to children under the age of 8 .

As a starting point, we consider carrying out a series of differential peculiarities for antibiotic therapy in children: $a$ ) During their early years, children do not have a medical history that suggests there may be adverse reactions or drug allergy; b) The larger proportion of water in a child's tissues, plus the greater sponginess of the bone tissue, permits a faster diffusion of the infection on the one hand, while on the other, the dose of the medication prescribed has necessarily to be properly adjusted; c) the anesthetic procedures in milk teeth in the process of rhizolysis can include carrying out intraligamental injections, although this will increase the possibility of bacteremia; $d$ ) the deficient oral hygiene in most children and the consumption of saccharose-rich foods, contribute to the increase in the number of germ colonies in the oral cavity, and thus the risk of bacteremia after oral treatment; and e) Resistance to antibiotics in children is extraordinarily complex as much for the high incidence rate as for the associated circumstances. 46,47

Various studies have evaluated the prevalence and extension of bacteremias following different dental procedures in children. It was demonstrated that just tooth brushing is associated with bacteremia in more than one in three children. ${ }^{96}$ Conservative dental treatment, in which wedges and matrices are placed, or in the case of orthodontic procedures such as placing and removing of bands, can lead to bacteremia in a significant number of children. ${ }^{97}$ During a simple tooth extraction bacteremia appears in $40-50 \%$ of the children examined. ${ }^{96}$ The highest levels of bacteremia are to be found after intraligamental injections in local anesthesia procedures ( $96.6 \%$ in children). ${ }^{98}$ In more than $50 \%$ of cases streptococci were isolated in the viridans group.

The level of oral hygiene has a considerable influence on the levels of bacteremia. For this reason, optimal oral hygiene could be the most important factor for the prevention of complications as a result of bacteremia; in the opinion of some authors, this is more influential than any antibiotic guidelines. 99 
Tabla 7. Pautas recomendadas para profilaxis de endocarditis

\begin{tabular}{|c|c|c|}
\hline Profilaxis & Adultos & Niños ${ }^{\dagger}$ \\
\hline Pauta estándar & Amoxicilina $2 \mathrm{~g}$ VO o IV & Amoxicilina 50 mg/kg VO. (máximo 2 g). \\
\hline \multirow[t]{3}{*}{ Alérgicos a betalactámicos } & Clindamicina $600 \mathrm{mg}$ VO & Clindamicina 20 mg/kg VO. (Máximo 600 mg) \\
\hline & Azitromicina 500 mg VO & Azitromicina $15 \mathrm{mg} / \mathrm{kg}$ VO \\
\hline & Claritromicina $500 \mathrm{mg}$ VO & Claritromicina 15 mg/kg VO \\
\hline Intolerancia oral & Ampicilina $2 \mathrm{~g}$ mg IM o IV & Ampicilina $50 \mathrm{mg} / \mathrm{kg}$ IM o IV \\
\hline \multirow[t]{2}{*}{ Intolerancia oral y alegia a penicilina } & Cefazolina $1 \mathrm{~g} \mathrm{IM} \mathrm{o} \mathrm{IV*}$ & Cefazolina 25 mg/kg IM o IV (máximo 1 g)* \\
\hline & Clindamicina $600 \mathrm{mg} \mathrm{IV}$ & Clindamicina 15 mg/kg IV. O IV. (Máximo 600 mg). \\
\hline
\end{tabular}

Table 7. Recommended guidelines for endocarditis prophylaxis

Prophylaxis

Standard

Allergy to betalactamase

Oral intolerance

Oral intolerance and allergy to penicillin

\section{Adults}

Amoxicillin $2 \mathrm{~g}$ PO or IV Clindamycin $600 \mathrm{mg} P O$ Azithromycin $500 \mathrm{mg} P O$ Clarithromycin $500 \mathrm{mg} P O$ Ampicillin $2 \mathrm{~g} \mathrm{mg} \mathrm{IM} \mathrm{or} \mathrm{IV}$ Cefazolin $1 \mathrm{~g} / \mathrm{M}$ or IV* Clindamycin $600 \mathrm{mg} \mathrm{IV}$

\section{Childrent}

Amoxicillin $50 \mathrm{mg} / \mathrm{kg}$ PO. (maximum $2 \mathrm{~g}$ ). Clindamycin 20 mg/kg PO. (Maximum 600 mg) Azithromycin $15 \mathrm{mg} / \mathrm{kg} P O$ Clarithromycin $15 \mathrm{mg} / \mathrm{kg} P O$ Ampicillin $50 \mathrm{mg} / \mathrm{kg}$ IM or IV Cefazolin $25 \mathrm{mg} / \mathrm{kg}$ IM or IV (maximum $1 \mathrm{~g}$ )* Clindamycin $15 \mathrm{mg} / \mathrm{kg}$ IV. or IV. (Maximum 600mg).

†The total pediatric dose should not surpass the adult dose; the follow-up dose should be half the initial dose.

${ }^{*}$ Cephalosporins should not be used in patients with Type I hypersensitivity to penicillin (rashes, angioedema or anaphylaxis).

PO: per os; IM: intramuscular; IV: intravenous

\section{Conclusiones}

1. La finalidad de la profilaxis antibiótica en cirugía es prevenir la posible aparición de infección a nivel de la herida quirúrgica, creando un estado de resistencia a los microorganismos mediante concentraciones antibióticas en sangre que eviten la proliferación y diseminación bacteriana a partir de la puerta de entrada que representa la herida quirúrgica.

2. El $10 \%$ de las prescripciones antibióticas se utiliza para infecciones odontogénicas, y una parte significativa de ellas se utiliza en profilaxis.

3. Los ensayos clínicos con antibióticos en patologías dentarias responden poco a los criterios metodológicos requeridos, y además no son lo suficientemente numerosos.

4. Como norma general, la profilaxis está indicada siempre que exista un riesgo importante de infección, ya sea por las características mismas de la operación o por las condiciones locales o generales del paciente.

5. El riesgo de contaminación del campo quirúrgico se incrementa con el tiempo de exposición y la complejidad del traumatismo producido y se minimiza con una adecuada técnica quirúrgica y con el buen estado del paciente. Pero el que se ha demostrado como factor más crítico y sujeto a debate es la profilaxis antibiótica.

6. En un estudio llevado a cabo en nuestro país se demostró que las complicaciones subsiguientes a la extracción del tercer molar son una enfermedad infecciosa y no exclusivamente inflamatoria, ya que se encontraron, con amoxicilina/ac. clavulánico
Dental trauma pathology represents an etiological factor of infection in the oral area, especially when there is direct exposure of pulp tissue and/or disturbances in the periodontal space. The possibilities of infection increase when, in addition to trauma to the hard or supporting dental tissues, there are open wounds in skin or mucosa.

\section{Prophylaxis of bacterial endocarditis}

These recommendations are a summary of the agreements and consensus documents of the American Academy of Cardiology ${ }^{37}$ that have since been accepted by most scientific and professional societies.

It will be applied to all patients susceptible to heart disease that are going to undergo a procedure with a risk of bacteremia in oral and maxillofacial surgery. The cardiopathies can be classified according to the risk of endocarditis as:

1. High-risk. Endovascular prosthesis, previous endocarditis, complex cyanogenic congenital cardiopathy or surgically constructed systemic-pulmonary fistulas.

2. Moderate-risk. Other congenital cardiopathies, acquired valvular disease, mitral prolapse with insufficiency, hypertrophic cardiomyopathy.

3. Low-risk. IAC ostium secundum, operated IAC or IVC, previous by-pass, mitral prolapse with no regurgitation, pacemakers, implanted defibrillators. 
Tabla 8. Profilaxis antibiótica en diferentes procedimientos

\begin{tabular}{|c|c|c|c|}
\hline Procedimiento & $\begin{array}{l}\text { Profilaxis paciente } \\
\text { de riesgo (SI/NO) }\end{array}$ & $\begin{array}{l}\text { Profilaxis paciente } \\
\text { sano (SI/NO) }\end{array}$ & Antibiótico y pauta (dosis pre-intervención) \\
\hline $\begin{array}{l}\text { Utilización de grapas para } \\
\text { aislamiento absoluto con dique de goma }\end{array}$ & $\mathrm{a} \quad \mathrm{SI}$ & NO & $\begin{array}{l}\text { Amoxicilina + Acido clavulánico } \\
\text { Adultos: } 2 \mathrm{~g}+125 \mathrm{~g} \text { V.O. } / 2 \mathrm{~g}+200 \mathrm{~g} \text { I.V. } \\
\text { Niños: } 50 \mathrm{mg}+6,25 \mathrm{mg} / \mathrm{kg} \text { V.O./ } 50 \mathrm{mg}+5 \mathrm{mg} / \mathrm{kg} \text { I.V. } \\
\text { Clindamicina } \\
\text { Adultos: } 600 \mathrm{mg} \text { V.O. / } 600 \mathrm{mg} \text { I.V. } \\
\text { Niños: } 20 \mathrm{mg} / \mathrm{kg} \text { V.O. } / 15 \mathrm{mg} / \mathrm{kg} \mathrm{I.V.}\end{array}$ \\
\hline Profilaxis periodontal e implantaria & SI & NO & $\begin{array}{l}\text { Amoxicilina + Acido Clavulánico } \\
\text { Adultos: } 2 \mathrm{~g}+125 \mathrm{~g} \text { V.O./2 g + } 200 \mathrm{~g} \text { I.V. } \\
\text { Niños: } 50 \mathrm{mg}+6,25 \mathrm{mg} / \mathrm{kg} \text { V.O./ } 50 \mathrm{mg}+5 \mathrm{mg} / \mathrm{kg} \text { I.V. } \\
\text { Clindamicina } \\
\text { Adultos: } 600 \mathrm{mg} \text { V.O. / } 600 \mathrm{mg} \text { I.V. } \\
\text { Niños: } 20 \mathrm{mg} / \mathrm{kg} \text { V.O. / } 15 \mathrm{mg} / \mathrm{kg} \text { I.V. }\end{array}$ \\
\hline Sondaje periodontal & $\mathrm{SI}$ & NO & $\begin{array}{l}\text { Amoxicilina + Acido clavulánico } \\
\text { Adultos: } 2 \mathrm{~g}+125 \mathrm{~g} \text { V.O./2 g }+200 \mathrm{~g} \text { I.V. } \\
\text { Niños: } 50 \mathrm{mg}+6,25 \mathrm{mg} / \mathrm{kg} \text { V.O. } / 50 \mathrm{mg}+5 \mathrm{mg} / \mathrm{kg} \text { I.V. } \\
\text { Clindamicina } \\
\text { Adultos: } 600 \mathrm{mg} \text { V.O. / } 600 \mathrm{mg} \text { I.V. } \\
\text { Niños: } 20 \mathrm{mg} / \mathrm{kg} \text { V.O. } / 15 \mathrm{mg} / \mathrm{kg} \text { I.V. }\end{array}$ \\
\hline Mantenimiento periodontal & SI & NO & $\begin{array}{l}\text { Amoxicilina + Acido clavulánico } \\
\text { Adultos: } 2 \mathrm{~g}+125 \mathrm{~g} \text { V.O. / } 2 \mathrm{~g}+200 \mathrm{~g} \mathrm{I.V.} \\
\text { Niños: } 50 \mathrm{mg}+6,25 \mathrm{mg} / \mathrm{kg} \text { V.O./ } 50 \mathrm{mg}+5 \mathrm{mg} / \mathrm{kg} \text { I.V. } \\
\text { Clindamicina } \\
\text { Adultos: } 600 \mathrm{mg} \text { V.O. / } 600 \mathrm{mg} \text { I.V. } \\
\text { Niños: } 20 \mathrm{mg} / \mathrm{kg} \text { V.O. / } 15 \mathrm{mg} / \mathrm{kg} \text { I.V. }\end{array}$ \\
\hline Anestesia intraligamentosa & $\mathrm{SI}$ & SI & $\begin{array}{l}\text { Amoxicilina + Acido clavulánico } \\
\text { Adultos: } 2 \mathrm{~g}+125 \mathrm{~g} \text { V.O. / } 2 \mathrm{~g}+200 \mathrm{~g} \mathrm{I.V.} \\
\text { Niños: } 50 \mathrm{mg}+6,25 \mathrm{mg} / \mathrm{kg} \text { V.O./ } 50 \mathrm{mg}+5 \mathrm{mg} / \mathrm{kg} \mathrm{I.V.} \\
\text { Clindamicina } \\
\text { Adultos: } 600 \mathrm{mg} \text { V.O. / } 600 \mathrm{mg} \text { I.V. } \\
\text { Niños: } 20 \mathrm{mg} / \mathrm{kg} \text { V.O. / } 15 \mathrm{mg} / \mathrm{kg} \text { I.V. }\end{array}$ \\
\hline Técnicas de anestesia troncular & $\mathrm{SI}$ & NO & $\begin{array}{l}\text { Amoxicilina + Acido clavulánico } \\
\text { Adultos: } 2 \mathrm{~g}+125 \mathrm{~g} \text { V.O. / } 2 \mathrm{~g}+200 \mathrm{~g} \mathrm{I.V.} \\
\text { Niños: } 50 \mathrm{mg}+6,25 \mathrm{mg} / \mathrm{kg} \text { V.O./ } 50 \mathrm{mg}+5 \mathrm{mg} / \mathrm{kg} \mathrm{I.V.} \\
\text { Clindamicina } \\
\text { Adultos: } 600 \mathrm{mg} \text { V.O. / } 600 \mathrm{mg} \text { I.V. } \\
\text { Niños: } 20 \mathrm{mg} / \mathrm{kg} \text { V.O. / } 15 \mathrm{mg} / \mathrm{kg} \text { I.V. }\end{array}$ \\
\hline Extracciones & $\mathrm{SI}$ & SI & $\begin{array}{l}\text { Amoxicilina + Acido clavulánico } \\
\text { Adultos: } 2 \mathrm{~g}+125 \mathrm{~g} \text { V.O. } / 2 \mathrm{~g}+200 \mathrm{~g} \mathrm{I.V.} \\
\text { Niños: } 50 \mathrm{mg}+6,25 \mathrm{mg} / \mathrm{kg} \text { V.O./ } 50 \mathrm{mg}+5 \mathrm{mg} / \mathrm{kg} \text { I.V. } \\
\text { Clindamicina } \\
\text { Adultos: } 600 \mathrm{mg} \text { V.O. / } 600 \mathrm{mg} \text { I.V. } \\
\text { Niños: } 20 \mathrm{mg} / \mathrm{kg} \text { V.O. / } 15 \mathrm{mg} / \mathrm{kg} \text { I.V. }\end{array}$ \\
\hline $\begin{array}{l}\text { Reimplantes dentarios } \\
\text { (intencionales y traumáticos) }\end{array}$ & $\mathrm{SI}$ & SI & $\begin{array}{l}\text { Amoxicilina + Acido Clavulánico } \\
\text { Adultos: } 2 \mathrm{~g}+125 \mathrm{~g} \text { V.O. / } 2 \mathrm{~g}+200 \mathrm{~g} \mathrm{I.V.} \\
\text { Niños: } 50 \mathrm{mg}+6,25 \mathrm{mg} / \mathrm{kg} \text { V.O./ } 50 \mathrm{mg}+5 \mathrm{mg} / \mathrm{kg} \text { I.V. } \\
\text { Clindamicina } \\
\text { Adultos: } 600 \mathrm{mg} \text { V.O. / } 600 \mathrm{mg} \text { I.V. } \\
\text { Niños: } 20 \mathrm{mg} / \mathrm{kg} \text { V.O. } / 15 \mathrm{mg} / \mathrm{kg} \text { I.V. }\end{array}$ \\
\hline Biopsias & $\mathrm{SI}$ & SI & $\begin{array}{l}\text { Amoxicilina + Acido clavulánico } \\
\text { Adultos: } 2 \mathrm{~g}+125 \mathrm{~g} \text { V.O. } / 2 \mathrm{~g}+200 \mathrm{~g} \text { I.V. } \\
\text { Niños: } 50 \mathrm{mg}+6,25 \mathrm{mg} / \mathrm{kg} \text { V.O./ } 50 \mathrm{mg}+5 \mathrm{mg} / \mathrm{kg} \text { I.V. } \\
\text { Clindamicina } \\
\text { Adultos: } 600 \mathrm{mg} \text { V.O. / } 600 \mathrm{mg} \text { I.V. } \\
\text { Niños: } 20 \mathrm{mg} / \mathrm{kg} \text { V.O. } / 15 \mathrm{mg} / \mathrm{kg} \mathrm{I.V.}\end{array}$ \\
\hline
\end{tabular}


Tabla 8. Continuación

\begin{tabular}{|c|c|c|c|}
\hline Procedimiento & $\begin{array}{l}\text { ofilaxis paciente } \\
\text { riesgo (SI/NO) }\end{array}$ & $\begin{array}{l}\text { Profilaxis paciente } \\
\text { sano (SI/NO) }\end{array}$ & Antibiótico y pauta (dosis pre-intervención) \\
\hline Incisiones para drenajes & SI & $\mathrm{SI}$ & $\begin{array}{l}\text { Amoxicilina + Acido clavulánico } \\
\text { Adultos: } 2 \mathrm{~g}+125 \mathrm{~g} \text { V.O. / } 2 \mathrm{~g}+200 \mathrm{~g} \text { I.V. } \\
\text { Niños: } 50 \mathrm{mg}+6,25 \mathrm{mg} / \mathrm{kg} \text { V.O./ } 50 \mathrm{mg}+5 \mathrm{mg} / \mathrm{kg} \text { I.V. } \\
\text { Clindamicina } \\
\text { Adultos: } 600 \mathrm{mg} \text { V.O. } / 600 \mathrm{mg} \text { I.V. } \\
\text { Niños: } 20 \mathrm{mg} / \mathrm{kg} \text { V.O. } / 15 \mathrm{mg} / \mathrm{kg} \text { I.V. }\end{array}$ \\
\hline Injertos oseos & SI & SI & $\begin{array}{l}\text { Amoxicilina + Acido clavulánico } \\
\text { Adultos: } 2 \mathrm{~g}+125 \mathrm{~g} \text { V.O. } / 2 \mathrm{~g}+200 \mathrm{~g} \text { I.V. } \\
\text { Niños: } 50 \mathrm{mg}+6,25 \mathrm{mg} / \mathrm{kg} \text { V.O./ } 50 \mathrm{mg}+5 \mathrm{mg} / \mathrm{kg} \text { I.V. } \\
\text { Clindamicina } \\
\text { Adultos: } 600 \mathrm{mg} \text { V.O. / } 600 \mathrm{mg} \text { I.V. } \\
\text { Niños: } 20 \mathrm{mg} / \mathrm{kg} \text { V.O. } / 15 \mathrm{mg} / \mathrm{kg} \text { I.V. }\end{array}$ \\
\hline Aplicación y retirada de suturas quirúrgicas & SI & NO & $\begin{array}{l}\text { Amoxicilina + Acido clavulánico } \\
\text { Adultos: } 2 \mathrm{~g}+125 \mathrm{~g} \text { V.O. } / 2 \mathrm{~g}+200 \mathrm{~g} \text { I.V. } \\
\text { Niños: } 50 \mathrm{mg}+6,25 \mathrm{mg} / \mathrm{kg} \text { V.O./ } 50 \mathrm{mg}+5 \mathrm{mg} / \mathrm{kg} \text { I.V. } \\
\text { Clindamicina } \\
\text { Adultos: } 600 \mathrm{mg} \text { V.O. / } 600 \mathrm{mg} \text { I.V. } \\
\text { Niños: } 20 \mathrm{mg} / \mathrm{kg} \text { V.O. } / 15 \mathrm{mg} / \mathrm{kg} \text { I.V. }\end{array}$ \\
\hline Raspado y alisado radicular & SI & SI & $\begin{array}{l}\text { Amoxicilina + Acido clavulánico } \\
\text { Adultos: } 2 \mathrm{~g}+125 \mathrm{~g} \text { V.O. } / 2 \mathrm{~g}+200 \mathrm{~g} \text { I.V. } \\
\text { Niños: } 50 \mathrm{mg}+6,25 \mathrm{mg} / \mathrm{kg} \text { V.O./ } 50 \mathrm{mg}+5 \mathrm{mg} / \mathrm{kg} \text { I.V. } \\
\text { Clindamicina } \\
\text { Adultos: } 600 \mathrm{mg} \text { V.O. / } 600 \mathrm{mg} \text { I.V. } \\
\text { Niños: } 20 \mathrm{mg} / \mathrm{kg} \text { V.O. } / 15 \mathrm{mg} / \mathrm{kg} \text { I.V. }\end{array}$ \\
\hline Cirugía periodontal & SI & SI & $\begin{array}{l}\text { Amoxicilina + Acido clavulánico } \\
\text { Adultos: } 2 \mathrm{~g}+125 \mathrm{~g} \text { V.O. } / 2 \mathrm{~g}+200 \mathrm{~g} \text { I.V. } \\
\text { Niños: } 50 \mathrm{mg}+6,25 \mathrm{mg} / \mathrm{kg} \text { V.O./ } 50 \mathrm{mg}+5 \mathrm{mg} / \mathrm{kg} \text { I.V. } \\
\text { Clindamicina } \\
\text { Adultos: } 600 \mathrm{mg} \text { V.O. / } 600 \mathrm{mg} \text { I.V. } \\
\text { Niños: } 20 \mathrm{mg} / \mathrm{kg} \text { V.O. } / 15 \mathrm{mg} / \mathrm{kg} \text { I.V. }\end{array}$ \\
\hline Cirugía de inserción de implantes & SI & SI & $\begin{array}{l}\text { Amoxicilina + Acido clavulánico } \\
\text { Adultos: } 2 \mathrm{~g}+125 \mathrm{~g} \text { V.O. } / 2 \mathrm{~g}+200 \mathrm{~g} \text { I.V. } \\
\text { Niños: } 50 \mathrm{mg}+6,25 \mathrm{mg} / \mathrm{kg} \text { V.O./ } 50 \mathrm{mg}+5 \mathrm{mg} / \mathrm{kg} \text { I.V. } \\
\text { Clindamicina } \\
\text { Adultos: } 600 \mathrm{mg} \text { V.O. / } 600 \mathrm{mg} \text { I.V. } \\
\text { Niños: } 20 \mathrm{mg} / \mathrm{kg} \text { V.O. } / 15 \mathrm{mg} / \mathrm{kg} \text { I.V. }\end{array}$ \\
\hline Cirugía mucogingival & SI & SI & $\begin{array}{l}\text { Amoxicilina + Acido clavulánico } \\
\text { Adultos: } 2 \mathrm{~g}+125 \mathrm{~g} \text { V.O. } / 2 \mathrm{~g}+200 \mathrm{~g} \text { I.V. } \\
\text { Niños: } 50 \mathrm{mg}+6,25 \mathrm{mg} / \mathrm{kg} \text { V.O. } / 50 \mathrm{mg}+5 \mathrm{mg} / \mathrm{kg} \text { I.V. } \\
\text { Clindamicina } \\
\text { Adultos: } 600 \mathrm{mg} \text { V.O. / } 600 \mathrm{mg} \text { I.V. } \\
\text { Niños: } 20 \mathrm{mg} / \mathrm{kg} \text { V.O. } / 15 \mathrm{mg} / \mathrm{kg} \text { I.V. }\end{array}$ \\
\hline Remoción de pilares de implantes & SI & NO & $\begin{array}{l}\text { Amoxicilina + Acido clavulánico } \\
\text { Adultos: } 2 \mathrm{~g}+125 \mathrm{~g} \text { V.O. } / 2 \mathrm{~g}+200 \mathrm{~g} \text { I.V. } \\
\text { Niños: } 50 \mathrm{mg}+6,25 \mathrm{mg} / \mathrm{kg} \text { V.O./ } 50 \mathrm{mg}+5 \mathrm{mg} / \mathrm{kg} \text { I.V. } \\
\text { Clindamicina } \\
\text { Adultos: } 600 \mathrm{mg} \text { V.O. / } 600 \mathrm{mg} \text { I.V. } \\
\text { Niños: } 20 \mathrm{mg} / \mathrm{kg} \text { V.O. } / 15 \mathrm{mg} / \mathrm{kg} \text { I.V. }\end{array}$ \\
\hline Cirugía endodóntica y apicectomía & SI & SI & $\begin{array}{l}\text { Amoxicilina + Acido clavulánico } \\
\text { Adultos: } 2 \mathrm{~g}+125 \mathrm{~g} \text { V.O. / } 2 \mathrm{~g}+200 \mathrm{~g} \text { I.V. } \\
\text { Niños: } 50 \mathrm{mg}+6,25 \mathrm{mg} / \mathrm{kg} \text { V.O./ } 50 \mathrm{mg}+5 \mathrm{mg} / \mathrm{kg} \text { I.V. } \\
\text { Clindamicina } \\
\text { Adultos: } 600 \mathrm{mg} \text { V.O. / } 600 \mathrm{mg} \text { I.V. } \\
\text { Niños: } 20 \mathrm{mg} / \mathrm{kg} \text { V.O. / } 15 \mathrm{mg} / \mathrm{kg} \text { I.V. }\end{array}$ \\
\hline
\end{tabular}


Tabla 8. Continuación

\begin{tabular}{|c|c|c|c|}
\hline Procedimiento & $\begin{array}{l}\text { laxis paciente } \\
\text { esgo (SI/NO) }\end{array}$ & $\begin{array}{l}\text { Profilaxis paciente } \\
\text { sano (SI/NO) }\end{array}$ & Antibiótico y pauta (dosis pre-intervención) \\
\hline $\begin{array}{l}\text { Procedimientos y colocación de cuñas, } \\
\text { matrices, bandas de ortodoncia y coronas } \\
\text { preformadas }\end{array}$ & SI & NO & $\begin{array}{l}\text { Amoxicilina + Acido clavulánico } \\
\text { Adultos: } 2 \mathrm{~g}+125 \mathrm{~g} \text { V.O. } / 2 \mathrm{~g}+200 \mathrm{~g} \text { I.V. } \\
\text { Niños: } 50 \mathrm{mg}+6,25 \mathrm{mg} / \mathrm{kg} \text { V.O./ } 50 \mathrm{mg}+5 \mathrm{mg} / \mathrm{kg} \text { I.V. } \\
\text { Clindamicina } \\
\text { Adultos: } 600 \mathrm{mg} \text { V.O. / } 600 \mathrm{mg} \text { I.V. } \\
\text { Niños: } 20 \mathrm{mg} / \mathrm{kg} \text { V.O. } / 15 \mathrm{mg} / \mathrm{kg} \text { I.V. }\end{array}$ \\
\hline $\begin{array}{l}\text { Colocación de aparatos de ortodoncia } \\
\text { removibles }\end{array}$ & NO & NO & \\
\hline Toma de impresiones & SI & NO & $\begin{array}{l}\text { Amoxicilina + Acido clavulánico } \\
\text { Adultos: } 2 \mathrm{~g}+125 \mathrm{~g} \text { V.O. } / 2 \mathrm{~g}+200 \mathrm{~g} \text { I.V. } \\
\text { Niños: } 50 \mathrm{mg}+6,25 \mathrm{mg} / \mathrm{kg} \text { V.O./ } 50 \mathrm{mg}+5 \mathrm{mg} / \mathrm{kg} \text { I.V. } \\
\text { Clindamicina } \\
\text { Adultos: } 600 \mathrm{mg} \text { V.O. / } 600 \mathrm{mg} \text { I.V. } \\
\text { Niños: } 20 \mathrm{mg} / \mathrm{kg} \text { V.O. } / 15 \mathrm{mg} / \mathrm{kg} \text { I.V. }\end{array}$ \\
\hline Colocación de hilo retractor & SI & NO & $\begin{array}{l}\text { Amoxicilina + Acido clavulánico } \\
\text { Adultos: } 2 \mathrm{~g}+125 \mathrm{~g} \text { V.O. } / 2 \mathrm{~g}+200 \mathrm{~g} \text { I.V. } \\
\text { Niños: } 50 \mathrm{mg}+6,25 \mathrm{mg} / \mathrm{kg} \text { V.O./ } 50 \mathrm{mg}+5 \mathrm{mg} / \mathrm{kg} \mathrm{I.V.} \\
\text { Clindamicina } \\
\text { Adultos: } 600 \mathrm{mg} \text { V.O. / } 600 \mathrm{mg} \text { I.V. } \\
\text { Niños: } 20 \mathrm{mg} / \mathrm{kg} \text { V.O. } / 15 \mathrm{mg} / \mathrm{kg} \text { I.V. }\end{array}$ \\
\hline $\begin{array}{l}\text { Procedimientos de tallado que } \\
\text { incluyan sangrado }\end{array}$ & SI & SI & $\begin{array}{l}\text { Amoxicilina + Acido clavulánico } \\
\text { Adultos: } 2 \mathrm{~g}+125 \mathrm{~g} \text { V.O. } / 2 \mathrm{~g}+200 \mathrm{~g} \text { I.V. } \\
\text { Niños: } 50 \mathrm{mg}+6,25 \mathrm{mg} / \mathrm{kg} \text { V.O./ } 50 \mathrm{mg}+5 \mathrm{mg} / \mathrm{kg} \text { I.V. } \\
\text { Clindamicina } \\
\text { Adultos: } 600 \mathrm{mg} \text { V.O. / } 600 \mathrm{mg} \text { I.V. } \\
\text { Niños: } 20 \mathrm{mg} / \mathrm{kg} \text { V.O. } / 15 \mathrm{mg} / \mathrm{kg} \text { I.V. }\end{array}$ \\
\hline Cirugía preprotésica & SI & $\mathrm{SI}$ & $\begin{array}{l}\text { Amoxicilina + Acido clavulánico } \\
\text { Adultos: } 2 \mathrm{~g}+125 \mathrm{~g} \text { V.O. } / 2 \mathrm{~g}+200 \mathrm{~g} \text { I.V. } \\
\text { Niños: } 50 \mathrm{mg}+6,25 \mathrm{mg} / \mathrm{kg} \text { V.O./ } 50 \mathrm{mg}+5 \mathrm{mg} / \mathrm{kg} \text { I.V. } \\
\text { Clindamicina } \\
\text { Adultos: } 600 \mathrm{mg} \text { V.O. } / 600 \mathrm{mg} \text { I.V. } \\
\text { Niños: } 20 \mathrm{mg} / \mathrm{kg} \text { V.O. } / 15 \mathrm{mg} / \mathrm{kg} \text { I.V. }\end{array}$ \\
\hline Cirugía ortognática & SI & $\mathrm{SI}$ & $\begin{array}{l}\text { Amoxicilina + Acido clavulánico } \\
\text { Adultos: } 2 \mathrm{~g}+125 \mathrm{~g} \text { V.O. } / 2 \mathrm{~g}+200 \mathrm{~g} \text { I.V. } \\
\text { Niños: } 50 \mathrm{mg}+6,25 \mathrm{mg} / \mathrm{kg} \text { V.O./ } 50 \mathrm{mg}+5 \mathrm{mg} / \mathrm{kg} \text { I.V. } \\
\text { Clindamicina } \\
\text { Adultos: } 600 \mathrm{mg} \text { V.O. / } 600 \mathrm{mg} \text { I.V. } \\
\text { Niños: } 20 \mathrm{mg} / \mathrm{kg} \text { V.O. } / 15 \mathrm{mg} / \mathrm{kg} \text { I.V. }\end{array}$ \\
\hline Traumatismos dentarios y alveolodentarios & $\mathrm{SI}$ & NO & $\begin{array}{l}\text { Amoxicilina + Acido Clavulánico } \\
\text { Adultos: } 2 \mathrm{~g}+125 \mathrm{~g} \text { V.O. } / 2 \mathrm{~g}+200 \mathrm{~g} \text { I.V. } \\
\text { Niños: } 50 \mathrm{mg}+6,25 \mathrm{mg} / \mathrm{kg} \text { V.O./ } 50 \mathrm{mg}+5 \mathrm{mg} / \mathrm{kg} \mathrm{I.V.} \\
\text { Clindamicina } \\
\text { Adultos: } 600 \mathrm{mg} \text { V.O. / } 600 \mathrm{mg} \text { I.V. } \\
\text { Niños: } 20 \mathrm{mg} / \mathrm{kg} \text { V.O. } / 15 \mathrm{mg} / \mathrm{kg} \text { I.V. }\end{array}$ \\
\hline Reducción de fracturas maxilares & SI & SI & $\begin{array}{l}\text { Amoxicilina + Acido clavulánico } \\
\text { Adultos: } 2 \mathrm{~g}+125 \mathrm{~g} \text { V.O. } / 2 \mathrm{~g}+200 \mathrm{~g} \text { I.V. } \\
\text { Niños: } 50 \mathrm{mg}+6,25 \mathrm{mg} / \mathrm{kg} \text { V.O./ } 50 \mathrm{mg}+5 \mathrm{mg} / \mathrm{kg} \text { I.V. } \\
\text { Clindamicina } \\
\text { Adultos: } 600 \mathrm{mg} \text { V.O. / } 600 \mathrm{mg} \text { I.V. } \\
\text { Niños: } 20 \mathrm{mg} / \mathrm{kg} \text { V.O. } / 15 \mathrm{mg} / \mathrm{kg} \text { I.V. }\end{array}$ \\
\hline
\end{tabular}


Tabla 8. Continuación

\begin{tabular}{|c|c|c|c|}
\hline Procedimiento & $\begin{array}{l}\text { Profilaxis paciente } \\
\text { de riesgo (SI/NO) }\end{array}$ & $\begin{array}{l}\text { Profilaxis paciente } \\
\text { sano (SI/NO) }\end{array}$ & Antibiótico y pauta (dosis pre-intervención) \\
\hline Cirugía de las glándulas salivales & SI & SI & $\begin{array}{l}\text { Amoxicilina + Acido clavulánico } \\
\text { Adultos: } 2 \mathrm{~g}+125 \mathrm{~g} \text { V.O. } / 2 \mathrm{~g}+200 \mathrm{~g} \text { I.V. } \\
\text { Niños: } 50 \mathrm{mg}+6,25 \mathrm{mg} / \mathrm{kg} \text { V.O./ } 50 \mathrm{mg}+5 \mathrm{mg} / \mathrm{kg} \text { I.V. } \\
\text { Clindamicina } \\
\text { Adultos: } 600 \mathrm{mg} \text { V.O. } / 600 \mathrm{mg} \text { I.V. } \\
\text { Niños: } 20 \mathrm{mg} / \mathrm{kg} \text { V.O. } / 15 \mathrm{mg} / \mathrm{kg} \text { I.V. }\end{array}$ \\
\hline Cirugía oncológica maxilofacial & SI & $\mathrm{SI}$ & $\begin{array}{l}\text { Amoxicilina + Acido clavulánico } \\
\text { Adultos: } 2 \mathrm{~g}+125 \mathrm{~g} \text { V.O. } / 2 \mathrm{~g}+200 \mathrm{~g} \text { I.V. } \\
\text { Niños: } 50 \mathrm{mg}+6,25 \mathrm{mg} / \mathrm{kg} \text { V.O./ } 50 \mathrm{mg}+5 \mathrm{mg} / \mathrm{kg} \text { I.V. } \\
\text { Clindamicina } \\
\text { Adultos: } 600 \mathrm{mgr} \text { V.O. / } 600 \mathrm{mgr} \text { I.V. } \\
\text { Niños: } 20 \mathrm{mg} / \mathrm{kg} \text { V.O. } / 15 \mathrm{mgr} / \mathrm{kg} \text { I.V. }\end{array}$ \\
\hline
\end{tabular}

Table 8. Antibiotic prophylaxis in different procedures

\section{Procedure \\ Prophylaxis in risk Prophylaxis in healthy Antibiotic and guidelines (pre-intervention dose) patients (YES/NO) patients (YES/NO)}

Use of staples for total isolation with rubber dam

Periodontal and implant prophylaxis

Periodontal probing

Periodontal maintenance

Intraligamental anesthesia

Techniques with trunk anesthesia
YES

NO

YES

NO

YES

YES

NO

YES

YES

YES
Amoxicillin + Clavulanic acid

Adults: $2 \mathrm{~g}+125 \mathrm{~g}$ P.O. $/ 2 \mathrm{~g}+200 \mathrm{~g}$ I.V.

Children: $50 \mathrm{mg}+6,25 \mathrm{mg} / \mathrm{kg}$ P.O./ $50 \mathrm{mg}+5 \mathrm{mg} / \mathrm{kg}$ I.V.

Clindamycin

Adults: $600 \mathrm{mg}$ P.O. / $600 \mathrm{mg}$ I.V.

Children: $20 \mathrm{mg} / \mathrm{kg}$ P.O. $/ 15 \mathrm{mg} / \mathrm{kg}$ I.V.

Amoxicillin + Clavulanic acid

Adults: $2 \mathrm{~g}+125 \mathrm{~g}$ P.O./ $2 \mathrm{~g}+200 \mathrm{~g}$ I.V.

Children: $50 \mathrm{mg}+6,25 \mathrm{mg} / \mathrm{kg}$ P.O./ $50 \mathrm{mg}+5 \mathrm{mg} / \mathrm{kg}$ I.V.

Clindamycin

Adults: $600 \mathrm{mg}$ P.O. / $600 \mathrm{mg}$ I.V.

Children: $20 \mathrm{mg} / \mathrm{kg}$ P.O. $/ 15 \mathrm{mg} / \mathrm{kg}$ I.V.

Amoxicillin + Clavulanic acid

Adults: $2 \mathrm{~g}+125 \mathrm{~g}$ P.O. $/ 2 \mathrm{~g}+200 \mathrm{~g}$ I.V.

Children: $50 \mathrm{mg}+6,25 \mathrm{mg} / \mathrm{kg}$ P.O./ $50 \mathrm{mg}+5 \mathrm{mg} / \mathrm{kg}$ I.V.

Clindamycin

Adults: $600 \mathrm{mg}$ P.O. / $600 \mathrm{mg}$ I.V.

Children: $20 \mathrm{mg} / \mathrm{kg}$ P.O / $15 \mathrm{mg} / \mathrm{kg}$ I.V.

Amoxicillin + Clavulanic Acid

Adults: $2 \mathrm{~g}+125 \mathrm{~g}$ P.O. $/ 2 \mathrm{~g}+200 \mathrm{~g}$ I.V.

Children: $50 \mathrm{mg}+6,25 \mathrm{mg} / \mathrm{kg}$ P.O./ $50 \mathrm{mg}+5 \mathrm{mg} / \mathrm{kg}$ I.V.

Clindamycin

Adults: $600 \mathrm{mg}$ P.O. / $600 \mathrm{mg}$ I.V.

Children: $20 \mathrm{mg} / \mathrm{kg}$ P.O. / $15 \mathrm{mg} / \mathrm{kg}$ I.V.

Amoxicillin + Clavulanic Acid

Adults: $2 \mathrm{~g}+125 \mathrm{~g}$ P.O. $/ 2 \mathrm{~g}+200 \mathrm{~g}$ I.V.

Children: $50 \mathrm{mg}+6,25 \mathrm{mg} / \mathrm{kg}$ P.O./ $50 \mathrm{mg}+5 \mathrm{mg} / \mathrm{kg}$ I.V.

Clindamycin

Adults: $600 \mathrm{mg}$ P.O. / $600 \mathrm{mg}$ I.V.

Children: $20 \mathrm{mg} / \mathrm{kg}$ P.O. $/ 15 \mathrm{mg} / \mathrm{kg}$ I.V.

Amoxicillin + Clavulanic acid

Adults: $2 \mathrm{~g}+125 \mathrm{~g}$ P.O. $/ 2 \mathrm{~g}+200 \mathrm{~g}$ I.V.

Children: $50 \mathrm{mg}+6,25 \mathrm{mg} / \mathrm{kg}$ P.O./ $50 \mathrm{mg}+5 \mathrm{mg} / \mathrm{kg} \mathrm{I.V.}$

Clindamycin

Adults: $600 \mathrm{mg}$ P.O. / $600 \mathrm{mg}$ I.V.

Children: $20 \mathrm{mg} / \mathrm{kg}$ P.O. / $15 \mathrm{mg} / \mathrm{kg}$ I.V. 
Table 8. Continue

\section{Procedure}

Extractions

Dental reimplants (intentional and traumatic) YES

Biopsies

YES

YES

Incisions for drains

YES

YES

Bone grafts

YES

YES

Application and removal of surgical sutures

YES

NO

Scaling and root planing

YES

YES

Periodontal surgery

Surgery for implant insertion
YES

YES
Amoxicillin + Clavulanic Acid

Adults: $2 \mathrm{~g}+125 \mathrm{~g}$ P.O. $/ 2 \mathrm{~g}+200 \mathrm{~g}$ I.V.

Children: $50 \mathrm{mg}+6,25 \mathrm{mg} / \mathrm{kg}$ P.O./ $50 \mathrm{mg}+5 \mathrm{mg} / \mathrm{kg}$ I.V.

Clindamycin

Adults: $600 \mathrm{mg}$ P.O. / 600mg I.V.

Children: $20 \mathrm{mg} / \mathrm{kg}$ P.O. / $15 \mathrm{mg} / \mathrm{kg}$ I.V.

Amoxicillin + Clavulanic Acid

Adults: $2 \mathrm{~g}+125 \mathrm{~g}$ P.O. $/ 2 \mathrm{~g}+200 \mathrm{~g}$ I.V.

Children: $50 \mathrm{mg}+6,25 \mathrm{mg} / \mathrm{kg}$ P.O./ $50 \mathrm{mg}+5 \mathrm{mg} / \mathrm{kg}$ I.V.

Clindamycin

Adults: $600 \mathrm{mg}$ P.O. / $600 \mathrm{mg}$ I.V.

Children: $20 \mathrm{mg} / \mathrm{kg}$ P.O. / $15 \mathrm{mg} / \mathrm{kg}$ I.V.

Amoxicillin + Clavulanic Acid

Adults: $2 \mathrm{~g}+125 \mathrm{~g}$ P.O. $/ 2 \mathrm{~g}+200 \mathrm{~g}$ I.V.

Children: $50 \mathrm{mg}+6,25 \mathrm{mg} / \mathrm{kg}$ P.O./ $50 \mathrm{mg}+5 \mathrm{mg} / \mathrm{kg}$ I.V.

Clindamycin

Adults: $600 \mathrm{mg}$ P.O. / $600 \mathrm{mg}$ I.V.

Children: $20 \mathrm{mg} / \mathrm{kg}$ P.O. / $15 \mathrm{mg} / \mathrm{kg}$ I.V.

Amoxicillin + Clavulanic Acid

Adults: $2 \mathrm{~g}+125 \mathrm{~g}$ P.O. $/ 2 \mathrm{~g}+200 \mathrm{~g}$ I.V.

Children: $50 \mathrm{mg}+6,25 \mathrm{mg} / \mathrm{kg}$ P.O./ $50 \mathrm{mg}+5 \mathrm{mg} / \mathrm{kg}$ I.V.

Clindamycin

Adults: $600 \mathrm{mg}$ P.O. / $600 \mathrm{mg}$ I.V.

Children: $20 \mathrm{mg} / \mathrm{kg}$ P.O. / $15 \mathrm{mg} / \mathrm{kg}$ I.V.

Amoxicillin + Clavulanic Acid

Adults: $2 \mathrm{~g}+125 \mathrm{~g}$ P.O. $/ 2 \mathrm{~g}+200 \mathrm{~g}$ I.V.

Children: $50 \mathrm{mg}+6,25 \mathrm{mg} / \mathrm{kg}$ P.O./ $50 \mathrm{mg}+5 \mathrm{mg} / \mathrm{kg} \mathrm{I.V}$.

Clindamycin

Adults: $600 \mathrm{mg}$ P.O. / $600 \mathrm{mg}$ I.V.

Children: $20 \mathrm{mg} / \mathrm{kg}$ P.O. / $15 \mathrm{mg} / \mathrm{kg}$ I.V.

Amoxicillin + Clavulanic Acid

Adults: $2 \mathrm{~g}+125 \mathrm{~g}$ P.O. $/ 2 \mathrm{~g}+200 \mathrm{~g}$ I.V.

Children: $50 \mathrm{mg}+6,25 \mathrm{mg} / \mathrm{kg}$ P.O./ $50 \mathrm{mg}+5 \mathrm{mg} / \mathrm{kg}$ I.V.

Clindamycin

Adults: $600 \mathrm{mg}$ P.O. / $600 \mathrm{mg}$ I.V.

Children: $20 \mathrm{mg} / \mathrm{kg}$ P.O. / $15 \mathrm{mg} / \mathrm{kg}$ I.V.

Amoxicillin + Clavulanic Acid

Adults: $2 \mathrm{~g}+125 \mathrm{~g}$ P.O. $/ 2 \mathrm{~g}+200 \mathrm{~g}$ I.V.

Children: $50 \mathrm{mg}+6,25 \mathrm{mg} / \mathrm{kg}$ P.O. $/ 50 \mathrm{mg}+5 \mathrm{mg} / \mathrm{kg}$ I.V.

Clindamycin

Adults: $600 \mathrm{mg}$ P.O. / $600 \mathrm{mg}$ I.V.

Children: $20 \mathrm{mg} / \mathrm{kg}$ P.O. / $15 \mathrm{mg} / \mathrm{kg}$ I.V.

Amoxicillin + Clavulanic Acid

Adults: $2 \mathrm{~g}+125 \mathrm{~g}$ P.O. $/ 2 \mathrm{~g}+200 \mathrm{~g}$ I.V.

Children: $50 \mathrm{mg}+6,25 \mathrm{mg} / \mathrm{kg}$ P.O./ $50 \mathrm{mg}+5 \mathrm{mg} / \mathrm{kg}$ I.V.

Clindamycin

Adults: $600 \mathrm{mg}$ P.O. / $600 \mathrm{mg}$ I.V.

Children: $20 \mathrm{mg} / \mathrm{kg}$ P.O. / $15 \mathrm{mg} / \mathrm{kg}$ I.V.

Amoxicillin + Clavulanic Acid

Adults: $2 \mathrm{~g}+125 \mathrm{~g}$ P.O. $/ 2 \mathrm{~g}+200 \mathrm{~g}$ I.V.

Children: $50 \mathrm{mg}+6,25 \mathrm{mg} / \mathrm{kg}$ P.O./ $50 \mathrm{mg}+5 \mathrm{mg} / \mathrm{kg}$ I.V.

Clindamycin

Adults: $600 \mathrm{mg}$ P.O. / $600 \mathrm{mg}$ I.V.

Children: $20 \mathrm{mg} / \mathrm{kg}$ P.O. / $15 \mathrm{mg} / \mathrm{kg}$ I.V. 
Table 8. Continue

\section{Procedure}

Mucogingival surgery

Removal of implant abutment

Endodontia

Endodontic surgery and apicectomy

YES

YES

Procedures and placing of wedges, matrices, YES orthodontic bands and preformed crowns

Placement of removable orthodontic appliances NO

Taking of impressions

YES

Placement of retraction cord

YES

Carving procedures that include bleeding

Amoxicillin + Clavulanic Acid

Adults: $2 \mathrm{~g}+125 \mathrm{~g}$ P.O. $/ 2 \mathrm{~g}+200 \mathrm{~g}$ I.V.

Children: $50 \mathrm{mg}+6,25 \mathrm{mg} / \mathrm{kg}$ P.O./ $50 \mathrm{mg}+5 \mathrm{mg} / \mathrm{kg}$ I.V.

Clindamycin

Adults: $600 \mathrm{mg}$ P.O. / $600 \mathrm{mg}$ I.V.

Children: $20 \mathrm{mg} / \mathrm{kg}$ P.O. / $15 \mathrm{mg} / \mathrm{kg}$ I.V.

Amoxicillin + Clavulanic Acid

Adults: $2 \mathrm{~g}+125 \mathrm{~g}$ P.O. $/ 2 \mathrm{~g}+200 \mathrm{~g}$ I.V.

Children: $50 \mathrm{mg}+6,25 \mathrm{mg} / \mathrm{kg}$ P.O./ $50 \mathrm{mg}+5 \mathrm{mg} / \mathrm{kg}$ I.V.

Clindamycin

Adults: $600 \mathrm{mg}$ P.O. / $600 \mathrm{mg}$ I.V.

Children: 20 mg/kg P.O. / $15 \mathrm{~m} \mathrm{g/kg} \mathrm{I.V.}$

Amoxicillin + Clavulanic Acid

Adults: $2 \mathrm{~g}+125 \mathrm{~g}$ P.O. $/ 2 \mathrm{~g}+200 \mathrm{~g}$ I.V.

Children: $50 \mathrm{mg}+6,25 \mathrm{mg} / \mathrm{kg}$ P.O./ $50 \mathrm{mg}+5 \mathrm{mg} / \mathrm{kg}$ I.V.

Clindamycin

Adults: $600 \mathrm{mg}$ P.O. / $600 \mathrm{mg}$ I.V.

Children: $20 \mathrm{mg} / \mathrm{kg}$ P.O. $/ 15 \mathrm{mg} / \mathrm{kg}$ I.V.

Amoxicillin + Clavulanic Acid

Adults: $2 \mathrm{~g}+125 \mathrm{~g}$ P.O. $/ 2 \mathrm{~g}+200 \mathrm{~g}$ I.V.

Children: $50 \mathrm{mg}+6,25 \mathrm{mg} / \mathrm{kg}$ P.O./ $50 \mathrm{mg}+5 \mathrm{mg} / \mathrm{kg}$ I.V.

Clindamycin

Adults: $600 \mathrm{mg}$ P.O. / $600 \mathrm{mg}$ I.V.

Children: $20 \mathrm{mg} / \mathrm{kg}$ P.O. / $15 \mathrm{mg} / \mathrm{kg}$ I.V.

NO

NO

NO

NO

Amoxicillin + Clavulanic Acid

Adults: $2 \mathrm{~g}+125 \mathrm{~g}$ P.O. $/ 2 \mathrm{~g}+200 \mathrm{~g}$ I.V.

Children: $50 \mathrm{mg}+6,25 \mathrm{mg} / \mathrm{kg}$ P.O./ $50 \mathrm{mg}+5 \mathrm{mg} / \mathrm{kg}$ I.V.

Clindamycin

Adults: $600 \mathrm{mg}$ P.O. / $600 \mathrm{mg}$ I.V.

Children: $20 \mathrm{mg} / \mathrm{kg}$ P.O. / $15 \mathrm{mg} / \mathrm{kg}$ I.V.

Amoxicillin + Clavulanic Acid

Adults: $2 \mathrm{~g}+125 \mathrm{~g}$ P.O. $/ 2 \mathrm{~g}+200 \mathrm{~g}$ I.V.

Children: $50 \mathrm{mg}+6,25 \mathrm{mg} / \mathrm{kg}$ P.O./ $50 \mathrm{mg}+5 \mathrm{mg} / \mathrm{kg}$ I.V.

Clindamycin

Adults: $600 \mathrm{mg}$ P.O. / $600 \mathrm{mg}$ I.V.

Children: $20 \mathrm{mg} / \mathrm{kg}$ P.O. / $15 \mathrm{mg} / \mathrm{kg}$ I.V.

Amoxicillin + Clavulanic Acid

Adults: $2 \mathrm{~g}+125 \mathrm{~g}$ P.O. $/ 2 \mathrm{~g}+200 \mathrm{~g}$ I.V.

Children: $50 \mathrm{mg}+6,25 \mathrm{mg} / \mathrm{kg}$ P.O. $/ 50 \mathrm{mg}+5 \mathrm{mg} / \mathrm{kg}$ I.V.

Clindamycin

Adults: $600 \mathrm{mg}$ P.O. / $600 \mathrm{mg}$ I.V.

Children: $20 \mathrm{mg} / \mathrm{kg}$ P.O. / $15 \mathrm{mg} / \mathrm{kg}$ I.V.

Amoxicillin + Clavulanic Acid

Adults: $2 \mathrm{~g}+125 \mathrm{~g}$ P.O. $/ 2 \mathrm{~g}+200 \mathrm{~g}$ I.V.

Children: $50 \mathrm{mg}+6,25 \mathrm{mg} / \mathrm{kg}$ P.O./ $50 \mathrm{mg}+5 \mathrm{mg} / \mathrm{kg}$ I.V.

Clindamycin

Adults: $600 \mathrm{mg}$ P.O. / $600 \mathrm{mg}$ I.V.

Children: $20 \mathrm{mg} / \mathrm{kg}$ P.O. $/ 15 \mathrm{mg} / \mathrm{kg}$ I.V.

Amoxicillin + Clavulanic Acid

Adults: $2 \mathrm{~g}+125 \mathrm{~g}$ P.O. $/ 2 \mathrm{~g}+200 \mathrm{~g}$ I.V.

Children: $50 \mathrm{mg}+6,25 \mathrm{mg} / \mathrm{kg}$ P.O./ $50 \mathrm{mg}+5 \mathrm{mg} / \mathrm{kg}$ I.V.

Clindamycin

Adults: $600 \mathrm{mg}$ P.O. / $600 \mathrm{mg}$ I.V.

Children: $20 \mathrm{mg} / \mathrm{kg}$ P.O. / $15 \mathrm{mg} / \mathrm{kg}$ I.V. 
Table 8. Continue

\section{Procedure}

Orthognathic surgery

Reduction of maxillary fractures

Surgery of salivary glands

Oncological maxillofacial surgery
Prophylaxis in risk Prophylaxis in healthy Antibiotic and guidelines (pre-intervention dose) patients (YES/NO) patients (YES/NO)
YES

YES

YES

NO

YES

YES

YES

YES

YES

YES
Amoxicillin + Clavulanic Acid

Adults: $2 \mathrm{~g}+125 \mathrm{~g}$ P.O. $/ 2 \mathrm{~g}+200 \mathrm{~g}$ I.V.

Children: $50 \mathrm{mg}+6,25 \mathrm{mg} / \mathrm{kg}$ P.O. $/ 50 \mathrm{mg}+5 \mathrm{mg} / \mathrm{kg}$ I.V. Clindamycin

Adults: $600 \mathrm{mg}$ P.O. / $600 \mathrm{mg}$ I.V.

Children: $20 \mathrm{mg} / \mathrm{kg}$ P.O. / $15 \mathrm{mgr} / \mathrm{kg}$ I.V.

Amoxicillin + Clavulanic Acid

Adults: $2 \mathrm{~g}+125 \mathrm{~g}$ P.O. $/ 2 \mathrm{~g}+200 \mathrm{~g}$ I.V.

Children: $50 \mathrm{mg}+6,25 \mathrm{mg} / \mathrm{kg}$ P.O./ $50 \mathrm{mg}+5 \mathrm{mg} / \mathrm{kg}$ I.V.

Clindamycin

Adults: $600 \mathrm{mg}$ P.O. / $600 \mathrm{mg}$ I.V.

Children: $20 \mathrm{mg} / \mathrm{kg}$ P.O. / $15 \mathrm{mg} / \mathrm{kg}$ I.V.

Amoxicillin + Clavulanic Acid

Adults: $2 \mathrm{~g}+125 \mathrm{~g}$ P.O. $/ 2 \mathrm{~g}+200 \mathrm{~g}$ I.V.

Children: $50 \mathrm{mg}+6,25 \mathrm{mg} / \mathrm{kg}$ P.O./ $50 \mathrm{mg}+5 \mathrm{mg} / \mathrm{kg}$ I.V.

Clindamycin

Adults: $600 \mathrm{mg}$ P.O. / $600 \mathrm{mg}$ I.V.

Children: $20 \mathrm{mg} / \mathrm{kg}$ P.O. / $15 \mathrm{mg} / \mathrm{kg}$ I.V.

Amoxicillin + Clavulanic Acid

Adults: $2 \mathrm{~g}+125 \mathrm{~g}$ P.O. $/ 2 \mathrm{~g}+200 \mathrm{~g}$ I.V.

Children: $50 \mathrm{mg}+6,25 \mathrm{mg} / \mathrm{kg}$ P.O./ $50 \mathrm{mg}+5 \mathrm{mg} / \mathrm{kg}$ I.V.

Clindamycin

Adults: $600 \mathrm{mg}$ P.O. / $600 \mathrm{mgr}$ I.V.

Children: 20 mg/kg P.O. / 15 mg/kg I.V.

Amoxicillin + Clavulanic Acid

Adults: $2 \mathrm{~g}+125 \mathrm{~g}$ P.O. $/ 2 \mathrm{~g}+200 \mathrm{~g}$ I.V.

Children: $50 \mathrm{mg}+6,25 \mathrm{mg} / \mathrm{kg}$ P.O./ $50 \mathrm{mg}+5 \mathrm{mg} / \mathrm{kg}$ I.V.

Clindamycin

Adults: $600 \mathrm{mg}$ P.O. / $600 \mathrm{mg}$ I.V.

Children: $20 \mathrm{mg} / \mathrm{kg}$ P.O. / $15 \mathrm{mg} / \mathrm{kg}$ I.V.

Patients requiring antibiotic prophylaxis are those who are high-risk and moderate risk, and who are going to undergo surgery in the maxillofacial area. The antibiotic guidelines are 1 hour previously if administered orally or $30 \mathrm{~min}$ utes previously if administered intravenously. Table 7 shows the antibiotics recommended in children and adults.

In addition, in children with a history of intravenous drug use, and certain syndromes (Down syndrome, Marfan's syndrome), there can be a risk of bacterial endocarditis because of the associated cardiac anomalies.

Although not supported by scientific evidence, the American Academy of Cardiology recommends that "individuals with a risk of developing bacterial endocarditis should maintain the best possible oral hygiene". Other authors have even stated that "maintaining a good standard of oral health, that reduces daily bacteremia, is probably more important when preventing endocarditis than the preventative administration of antibiotics before specific dental surgery. " Emphasis has to be made therefore on maintaining good periodontal health as a way of preventing bacteremias and therefore the risk of endocarditis. 
bacteriemia. En el sujeto sano la profilaxis se basa exclusivamente en el riesgo del procedimiento.

11. El antibiótico a elegir (en caso de considerar necesaria la profilaxis por el tipo de procedimiento y tipo de paciente) debe cumplir las siguientes características:

- Espectro bacteriano adecuado, cubriendo todas las especies involucradas en las infecciones polimicrobianas locales o monomicrobianas focales distales, incluyendo microorganismos aerobios, microaerófilos, sin olvidar los anaerobios que debido a la dificultad en su aislamiento en ocasiones no son considerados prevalentes en bacteriemias de origen oral.

- Espectro clínico amplio, para cubrir el mayor número de procedimientos odontológicos

- Espectro ecológico restringido para limitar al máximo los efectos sobre la flora saprófita habitual.

- Farmacocinética y farmacodinamia adecuadas, para permitir su utilización en monodosis pre-operatoria en el caso de la profilaxis, o intervalos de dosificación amplios en el tratamiento preventivo de corta duración, con semividas o formulaciones de liberación prolongada que mantengan concentraciones adecuadas a nivel local (fluido gingival) o sistémico (suero) durante todo el tiempo que dure el procedimiento odontológico (profilaxis)

- Perfil de seguridad adecuado, incluso en población infantil y tercera edad.

\section{Agradecimientos}

A los siguientes colaboradores por su ayuda con la búsqueda bibliográfica y participación en algunas de las secciones del documento: Lorenzo Aguilar Alfaro, Juan Carlos Asurmendi, Maria José Barra Soto, Antonio Bowen, Pedro Buitrago Vega, Alvaro Del Amo, Eva Santa Eulalia Troisfontaines, Pedro Fernández Palacios, Rafael Flores Ruiz, Manuel García Calderón, Ignacio García Moris, Maria José Giménez Mestre, Conchita González-Morán, Pilar Hita Iglesias, Luis Ilzarbe, Pedro Infante Cossío, Amparo Jimenez Planas, Carlos Labaig, Natale Magallanes Abad, Jose E. Martín Herrero, Manuel Menéndez Núñez, Francisco Pina, Rafael Poveda Roda, José Quijada,, Daniel Torres Lagares, Manuel Zaragoza.

A GlaxoSmithKline por su apoyo para hacer realidad el documento.

\section{Bibliografía}

1. Bascones A, Aguirre JM, Bermejo A, Blanco A, Gay-Escoda C, González-Moles MA, Gutiérrez Pérez JL, Jiménez Soriano Y, Liébaba Ureña J, López-Marcos JF, Maestre Vera JR, Perea Pérez EJ, Prieto Prieto J, de Vicente Rodríguez JC. Documento de consenso sobre el tratamiento antimicrobiano de las infecciones bacterianas odontogénicas. Med Oral Patol Oral Cir Bucal 2004;9:363-76.

2. Prescription des antibiotiques en odontologie et stomatologie. Recommandations et argumentaire. Agence Française de Sécurité Sanitaire des Produits de la Santé. 2001 (www.afssaps.sante.fr).

3. Martínez Lacasa J, Jiménez J, Ferrás VA, García-Rey C, Bosom M, Solá-Morales O, Aguilar L, Garau J. A double blind, placebo-controlled, randosmised, comparati-
Another aspect that should be clarified in the future is if the bacteremias associated with active periodontitis are reduced significantly with periodontal infection control and therefore, if treatment is an efficient form of prophylaxis against endocarditis. Periodontal pathogenic bacteria rarely cause endocarditis although the group of microorganisms called HACEK among which is Actinobacillus actinomycetemcomitans and Eikenella Corrodens has increased in etiological importance, which would sustain the hypothesis that the increase is relative to the importance of periodontal disease in the etiology of endocarditis.

\section{Conclusions}

1. The aim of antibiotic prophylaxis in surgery is to prevent the possible appearance of infection of the surgical wound, creating a state of resistance to micro-organisms by means of antibiotic concentrations in blood that avoid the proliferation and dissemination of bacteria as from the point of entry represented by the surgical wound.

2. $10 \%$ of antibiotic prescriptions are used for odontogenic infections, and a significant part of these is used in prophylaxis.

3. Clinical trials with antibiotics in dental pathologies respond little to the required methodological criteria and, in addition to this, they are not sufficiently numerous.

4. As a general rule, prophylaxis is indicated whenever there is considerable risk of infection, either because of the characteristics of the operation or because of the local or general condition of the patient.

5. The risk of contamination of the surgical field increases with exposure time and the complexity of the trauma produced, and it is minimized with suitable surgical techniques and with the good health of the patient. But what has been demonstrated as being the most critical and debated factor is antibiotic prophylaxis.

6. In a study carried out in our country, it was demonstrated that complications following the extraction of third molars are infectious and not exclusively inflammatory, as it was found that with amoxicillin/clavulanic acid 2000/125 $\mathrm{mg}$, that there were significant differences in the rate of complications between the groups that received treatment (5 days), preoperative prophylaxis (single dose) and a placebo (2.7, 5.3 and $16 \%$ respectively). The rates of infectious complication were higher in the case of osteotomies or longer surgery.

7. Local polymicrobial infections are cutaneous-mucosal or bone infections that are produced as a result of invasive dental procedures.

8. Monomicrobial systemic infections are infections that arise in patients with a focus susceptible to infection (endocardial changes, bone or joint prostheses), in patients with greater susceptibility.

9. The physician's criterion for choosing antibiotic prophy- 
ve phase III clinical trial of pharmacokinetically enhanced amoxicillin/clavulanate $2000 / 125$, as prophylaxis or as treatment versus placebo for infectious and inflammatory morbidity after third mandibula removal. Program and Abstracts of the 43rd InterScience Conference on Antimicrobial Agents and Chemotherapy, Chicago 2003. American Society for Microbiology, Washington, DC.

4. Esposito M, Coulthard P, Oliver R, Thomsen P, Worthington HV. Antibiotics to prevent complications following dental implant treatment. Cochrane Database Syst Rev 2003;(3):CD004152.

5. Esposito M, Hirsch JM, Lekholm U, Thomsen P. Biological factors contributing to failures of osseointegrated oral implants. (I). Success criteria and epidemiology. Eur J Oral Sci 1998; 106:527-51.

6. Esposito M, Hirsch JM, Lekholm U, Thomsen P. Biological factors contributing to failures of osseointegrated oral implants. (II). Etiopathogenesis. Eur / Oral Sci 1998; 106:721-64.

7. Offenbacher S, Katz V, Fertik G, Collins J, Boyd D, Maynor G, McKaig R, Beck J. Periodontal infection as a possible risk factor for preterm low birth weight. J Periodontol 1996;67(10 Suppl):1103-13.

8. Overholser CD, Moreillon P, Glauser MP. Experimental bacterial endocarditis after dental extractions in rats with periodontitis. J Infect Dis 1987;155:107-12.

9. Tomás Carmona I, Diz Dios P, Scully C. An update on the controversies in bacterial endocarditis of oral origin. Oral Surg Oral Med Oral Pathol 2002;93:66070.

10. Longman LP, Preston AJ, Martin MV, Wilson NH. Endodontics in the adult patient: the role of antibiotics. J Dent 2000;28:539-48.

11. Drucker DB, Gomes BP, Lilley JD. Role of anaerobic species in endodontic infection. Clin Infect Dis 1997;25:S220-1.

12. Sixou JL, Magaud C, Jolivet-Gougeon A, Cormier M, Bonnaure-Mallet M. Evaluation of the mandibular third molar pericoronitis flora and its susceptibility to different antibiotics prescribed in france. J Clin Microbiol 2003;41:5794-7.

13. Sixou JL, Magaud C, Jolivet-Gougeon A, Cormier M, Bonnaure-Mallet M. Microbiology of mandibular third molar pericoronitis: incidence of beta-lactamaseproducing bacteria. Oral Surg Oral Med Oral Pathol Oral Radiol Endod 2003; 95:655-9.

14. Sobottka I, Cachovan G, Sturenburg E, Ahlers MO, Laufs R, Platzer U, Mack D. In vitro activity of moxifloxacin against bacteria isolated from odontogenic abscesses. Antimicrob Agents Chemother 2002;46:4019-21.

15. Loesche W], Grossman NS. Periodontal disease as a specific, albeit chronic, infection: diagnosis and treatment. Clin Microbiol Rev 2001;14:727-52.

16. Okell CC, Elliott D. Bacteremia and oral sepsis with special reference to aetiology of bacterial endocarditis. Lancet 1935;2:869-72.

17. Fine DH, Hammond BF, Loesche WJ. Clinical use of antibiotics in dental practice. Int J Antimicrob Agents 1998;9:235-8.

18. Jacobson JJ, Patel B, Asher G, Woolliscroft JO, Schaberg D. Oral staphylococcus in older subjects with rheumatoid arthritis. J Am Geriatr Soc 1997;45:590-3.

19. Berbari EF, Cockerill FR 3rd, Steckelberg JM. Infective endocarditis due to unusual or fastidious microorganisms. Mayo Clin Proc 1997;72:532-42.

20. Okabe K, Nakagawa K, Yamamoto E. Factors affecting the occurrence of bacteremia associated with tooth extraction. Int J Oral Maxillofac Surg 1995;24:239-42.

21. Rajasuo A, Perkki K, Nyfors S, Jousimies-Somer H, Meurman JH. Bacteremia following surgical dental extraction with an emphasis on anaerobic strains. J Dent Res 2004;83:170-4.

22. Stone HH, Haney BB, Kolb LD, et al. Prophylactic and preventive antibiotic therapy: Timing, duration and economic. Ann Surg 1979;189:691-99.

23. Dipiro JT, Cheung RPF, Borden TA Jr. Single dose systemic antibiotic prophylaxis of surgical wound infections. Am / Surg 1986;152:552-9. laxis or not, should be based on the cost benefit-risk concept. In the last instance the decision for prophylaxis is at the discretion of the physician according to the equation: risk = damage $x$ possibility of experiencing it. This approach is subjective.

10. To this end patients can be classified into: a) healthy patients, b) patients with local or systemic risk of infection and c) patients with risk factors for focal infection after bacteremia. In the healthy individual, prophylaxis is based exclusively on the risk of the procedure.

11. The antibiotic of choice (if prophylaxis is considered necessary because of the type of procedure and type of patient) should comply with the following characteristics.

- Adequate bacterial spectrum, covering all the species involved in local polymicrobial infections or distal focal monomicrobial infections, including aerobic microorganisms, microaerophile, not forgetting anaerobes that because there is difficulty isolating them, are sometimes not considered prevalent in oral-origin bacteremias.

- Wide clinical spectrum for covering the largest number of dental procedures.

- Restricted ecological spectrum in order to limit to the maximum the effects on the usual saprophyte flora.

- Adequate pharmacokinetics and pharmacodynamics to allow use in single preoperative doses in the case of prophylaxis, or longer dose intervals in short-term preventative treatment, with half-lives or with a prolonged release formula that maintain adequate concentrations at a local level (gingival fluid) or systemic (serum) during the entire time the dental procedure lasts (prophylaxis).

- Adequate safety profile, including the pediatric and elderly populations. 
24. Cisneros JM, Rodríguez-Baño J, Mensa J, y cols. Profilaxis con antimicrobianos en cirugía. Enferm Infecc Microbiol Clin 2002;20:335-40.

25. García-Rodríguez JA, Prieto J, Gobernado M, y cols. Documento de consenso sobre quimioprofilaxis quirúrgica. Rev Esp Quimioterap 2000;13:205-13.

26. French Health Products Safety Agency (Afssaps). Prescribing antibiotics in odontology and stomatology. Recommendations by the French Health Products Safety Agency. Fundam Clin Pharmacol 2003;17:725-9.

27. Martin MV, Butterworth ML, Longman LP. Infective endocarditis and the dental practitioner: a review of 53 cases involving litigation. $\mathrm{Br}$ Dent / 1997; 182: 465-8.

28. Wynn RL, Meiller TF, Crossley H, Overholser CD. Recent reports calling for reduction of antibiotic prophylaxis in dental procedures: a response. Gen Dent 1999; 47:124-30.

29. Aguilar L, García-Rey G, Giménez MJ. Presión antibiótica, desarrollo de resistencias en Streptococcus pneumoniae y fracaso clínico. Un círculo no tan viciosos para algunos antibióticos. Rev Esp Quimioterap 2001;14:17-21.

30. Baquero F, Baquero-Artigao G, Canton R, Garcia-Rey C. Antibiotic consumption and resistance selection in Streptococcus pneumoniae. I Antimicrob Chemother 2002;50(Suppl S2):27-37.

31. Schrag SJ, Peña C, Fernández J, Sánchez J, Gómez V, Pérez E, Feris JM, Besser RE. Effect of short-course, high-dose amoxicillin therapy on resistant pneumococcal carriage: a randomized trial. JAMA 2001;286:49-56.

32. Tong DC, Rothwell BR. Antibiotic prophylaxis in dentistry: a review and practice recommendations. J Am Dent Assoc 2000;131:366-74.

33. Westerman EL. Postsplenectomy sepsis and antibiotic prophylaxis before dental work. Am J Infect Control 1991;19:254-5.

34. Sandre RM, Shafran SD. Infective endocarditis: review of 135 cases over 9 years. Clin Infect Dis 1996;22:276-86.

35. Hall G, Heimdahl A, Nord CE. Effects of prophylactic administration of cefaclor on transient bacteremia after dental extraction. Eur / Clin Microbiol Infect Dis 1996;15:646-9.

36. Hall G, Nord CE, Heimdahl A. Elimination of bacteraemia after dental extraction: comparison of erythromycin and clindamycin for prophylaxis of infective endocarditis. J Antimicrob Chemother 1996;37:783-95.

37. Dajani AS, Taubert KA, Wilson W, Bolger AF, Bayer A, Ferrieri P, Gewitz MH, Shulman ST, Nouri S, Newburger JW, Hutto C, Pallasch T], Gage TW, Levison ME, Peter G, Zuccaro G Jr. Prevention of bacterial endocarditis: recommendations by the American Heart Association. JAMA 1997;277:1794-1801.

38. Seymour RA, Lowry R, Whitworth JM, Martin MV. Infective endocarditis, dentistry and antibiotic prophylaxis; time for a rethink? Br Dent / 2000;189:610-6.

39. Shrout MK, Scarbrough F, Powell BJ. Dental care and the prosthetic joint patient: a survey of orthopedic surgeons and general dentists. I Am Dent Assoc 1994; 125:429-36.

40. Altemeier WA, Burke JP, Pruitt BA, Sandusky WR. Manual of control on infection in surgical patients. JB Lippincott Co., Philadelphia, 1976.

41. Liñares J, Martin-Herrero JE. Bases farmacomicrobiológicas del tratamiento antibiótico de las enfermedades periodontales y periimplantarias. Av Odontoestomatol 2003;(especial):23-33.

42. Barberán J, Giménez MJ, Aguilar L, Prieto J. Evidencia científica y concepción global del tratamiento empírico de la infección de vías respiratorias bajas en la comunidad. Rev Esp Quimioterap 2004;17:317-24.
43. Isla A, Canut A, Rodriguez-Gascon A, Labora A, Ardanza-Trevijano B, Solinis MA, Pedraz JL. Análisis farmacocinético/farmacodinámico (PK/PD) de la antibioterapia en odontoestomatología. Enferm Infecc Microbiol Clin 2005;23:116-21.

44. Granizo JJ, Aguilar L, Casal J, Garcia-Rey C, Dal-Re R, Baquero F. Streptococcus pneumoniae resistance to erythromycin and penicillin in relation to macrolide and beta-lactam consumption in Spain (1979-1997). J Antimicrob Chemother 2000;46:767-73.

45. Granizo JJ, Aguilar L, Casal J, Dal-Re R, Baquero F. Streptococcus pyogenes resistance to erythromycin in relation to macrolide consumption in Spain (1986-1997). J Antimicrob Chemother 2000;46:959-64.

46. Garcia-Rey C, Aguilar L, Baquero F, Casal J, Martin JE. Pharmacoepidemiological analysis of provincial differences between consumption of macrolides and rates of erythromycin resistance among Streptococcus pyogenes isolates in Spain. J Clin Microbiol 2002;40:2959-63.

47. Garcia-Rey C, Aguilar L, Baquero F, Casal J, Dal-Re R. Importance of local variations in antibiotic consumption and geographical differences of erythromycin and penicillin resistance in Streptococcus pneumoniae. J Clin Microbiol 2002; 40:159-64.

48. Gomez-Lus R, Granizo JJ, Aguilar L, Bouza E, Gutierrez A, Garcia-deLomas J. Is there an ecological relationship between rates of antibiotic resistance of species of the genus Streptococcus? The Spanish Surveillance Group for Respiratory Pathogens. I Clin Microbiol 1999;37:3384-6.

49. Rodriguez-Avial I, Rodriguez-Avial C, Culebras E, Picazo JJ. In vitro activity of telithromycin against viridans group streptococci and Streptococcus bovis isolated from blood: antimicrobial susceptibility patterns in different groups of species. Antimicrob Agents Chemother 2005;49:820-3.

50. Rodriguez-Avial I, Rodriguez-Avial C, Culebras E, Picazo JJ. Distribution of tetracycline resistance genes tet $(\mathrm{M})$, tet( $\mathrm{O})$, tet $(\mathrm{L})$ and tet( $\mathrm{K})$ in blood isolates of viridans group streptococci harbouring erm(B) and mef(A) genes. Susceptibility to quinupristin/dalfopristin and linezolid. Int J Antimicrob Agents 2003;21:536-41.

51. Tomás I, Limeres J, Diz P. Antibiotic prophylaxis. BDJ 2005;198:60-61.

52. Tomas I, Alvarez M, Limeres J, Otero JL, Saavedra E, Lopez-Melendez C, Diz P. In vitro activity of moxifloxacin compared to other antimicrobials against streptococci isolated from iatrogenic oral bacteremia in Spain. Oral Microbiol Immunol 2004;19:331-5.

53. Bascones A, Mansó F. Infecciones odontógenas en la cavidad bucal y región maxilofacial. Av Odontoestomatol 1994;10(Supl. A):5-26.

54. Tenenbaum JF, Gallion C, Dahan M. Amoxicillin and clavulanic acid concentrations in gingival crevicular fluid. / Clin Periodontol 1997;24: 804-7.

55. Poulet PP, Duffaut D, Barthet P, Brumpt I. Concentrations and in vivo antibacterial activity of spiramycin and metronidazole in patients with periodontitis treated with high-dose metronidazole and the spiramycin/metronidazole combination. J Antimicrob Chemother 2005;55:34751.

56. Isla A, Canut A, Gascon AR, Labora A, Ardanza-Trevijano B, Solinis MA, Pedraz JL. Pharmacokinetic/Pharmacodynamic evaluation of antimicrobial treatments of orofacial odontogenic infections. Clin Pharmacokinet 2005;44:305-16.

57. Isla A, Canut A, Rodríguez-Gascón A, Pedraz JL. Farmacocinética/farmacodinámica de la formulación de amoxicilina/ácido clavulánico 
2000/125 mg en odontoestomatología. Enferm Infecc Microbiol Clin 2005;23:387.

58. Liébana J, Ponton J, Benito L. Bacilos grampositivos anaerobios facultativos de interés oral. En Liébana J. Ed. Micro-biología Oral. $2^{\text {a }}$ ed. Madrid, Interamericana McGraw-Hill. 2002;345-54.

59. Liébana J, Baca P, Rodriguez-Avial C. Microbiología de las placas dentales. En Liébana J. Ed. Micro-biología Oral. $2^{a}$ ed. Madrid, Interamericana McGraw-Hill. 2002;541-59.

60. Mejàre I, Brännström $\mathrm{M}$ : Deep bacterial penetration of early proximal caries lesions in young human premolars. J Dent Children 1985;103-107.

61. Seppä L, Alakuijala P, Karvonen I : A scanning electron microscopic study of bacterial penetration of human enamel in incipient caries. Archs Oral Biol 1985; 30:595-598.

62. Bruchner D, Colonna P, Berrazo B. Nomenclatura for aerobic and facultative bacteria. Clin Infect Dis 1999;29:713-23.

63. Lundeen TF, Roberson TM. Cariología. Lesión, etiología, prevención y control. En: Studervant CM, Roberson TM, Heymann HO, Studervant JR:

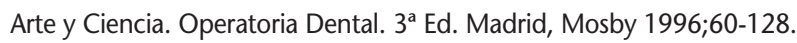

64. Pumarola J. Microbiología Endodóntica. En: CANALDA C, BRAU E: Endodoncia. Técnicas clínicas y bases científicas. Barcelona, Masson 2001;29-41.

65. Figueres KH, Douglas CWI. Actinomycosis associated with a roottreated tooth: report of case. Int Endod / 1991;24:326-9.

66. Molander A, Reit C, Dahlen G, Kvist T. Microbiological status of rootfilled teeth with apical peridontitis. Int Endod / 1998;31:1-7.

67. Barnard D, Davies J, Figdor D. Susceptibility of Actinomyces israelli to antibiotics, sodium hypochlorite and calcium hydroxide. Int Endod I 1996;29:320-6.

68. Vigil GV, Wayman BE, Dazey SE, Fowler CB, Bradley Jr DV. Identification and antaibiotic sensitivity of bacteria isolated from periapical lesions. J Endod 1997; 23:110-4.

69. Sands T, Pynn BR, Nenniger S. Third molar surgery: current concepts and controversies. Part 2. Oral Health 1993;83:19, 21-2, 27-30.

70. Zeitler DL. Prophylactic antibiotics for third molar surgery: a dissenting opinion. J Oral Maxillofac Surg 1995;53:61-4.

71. Kaziro GS. Metronidazole (Flagyl) and Arnica Montana in the prevention of post-surgical complications, a comparative placebo controlled clinical trial. Br J Oral Maxillofac Surg 1984;22:42-9.

72. Mitchell DA. A controlled clinical trial of prophylactic tinidazole for chemoprophylaxis in third molar surgery. Br Dent J 1986;160:284-6.

73. Macgregor AJ, Addy A. Value of penicillin in the prevention of pain, swelling and trismus following the removal of ectopic mandibular third molars. Int J Oral Surg 1980;9:166-72.

74. Piecuch JF, Arzadon J, Lieblich SE. Prophylactic antibiotics for third molar surgery: a supportive opinion. J Oral Maxillofac Surg 1995;53:5360.

75. Esposito M, Coulthard P, Oliver R, Thomsen P, Worthington HV. Antibiotics to prevent complications following dental implant treatment. The Cochrane Database of Systematic Reviews 2003.

76. Gynther G, Kondell P, Moberg L, Heimdahl A. Dental implant instaIlation without antibiotic prophylaxis. Oral Sug Oral Med Oral Pathol Oral Radiol Endo 1998;85:509-11.

77. Binanhmed A, Stoykewych A, Peterson L. Single preoperative dose versus long-term prophylactic antibiotic regimens in dental implant surgery. Int J Oral Maxillofac Implants 2005;20:115-7.
78. Sindet-Pedersen. The prophylactic use of antibiotics in periodontics. In Proceedings of the 2nd European Workshop on Periodontology. Quintassence. Berlin 1997;30-37.

79. Daly C, Mitchell D, Grossberg D, Highfield J, Stewart D. Bacteraemia caused by periodontal probing. Aust Dent / 1997;42:77-80.

80. Daly CG, Mitchell DH, Highfield JE, Grossberg DE, Stewart D. Bacteremia due to periodontal probing: a clinical and microbiological investigation. Periodontol 2001;72:210-4.

81. Bowersock TL, Wu CC, Inskeep GA, Chester ST. Prevention of bacteremia in dogs undergoing dental scaling by prior administration of oral clindamycin or chlorhexidine oral rinse. / Vet Dent 2000;17:11-6.

82. Allison C, Simor AE, Mock D, Tenenbaum HC. Prosol-chlorhexidine irrigation reduces the incidence of bacteremia during ultrasonic scaling with the Cavi-Med: a pilot investigation. J Can Dent Assoc 1993;59:676-82.

83. Lofthus JE, Waki MY, Jolkovsky DL, Otomo-Corgel J, Newman MG, Flemmig T, Nachnani S. Bacteraemia following subgingival irrigation and scaling and root planing. J Periodontol 1991;62:602-7.

84. Witzenberger T, O'Leary T], Gillette WB. Effect of a local germicide on the occurrence of bacteremia during subgingival scaling. I Periodontol 1982;53:172-9.

85. Appleman MD, Sutter VL, Sims TN. Value of antibiotic prophylaxis in periodontal surgery. J Periodontol 1982;53(5):319-24.

86. Powell CA, Mealey BL, Deas DE, McDonnell HT, Moritz AJ. Post-surgical infections: prevalence associated with various periodontal surgical procedures. J Periodontol 2005;76:329-33.

87. Wampole HS, Allen AL, Gross A. The incidence of transient bacteremia during periodontal dressing change. J Periodontol 1978;49:462-4.

88. Schlein RA, Kudlick EM, Reindorf CA, Gregory J, Royal GC. Tootbrushing and transient bacteraemia in patients undergoing orthodontic treatment. Am J Orthod Dentof Orthop 1991;99:466-72.

89. Sconyers JR, Crawford JJ, Moriarity JD. Relationship of bacteraemia to toothbrishing in patients with periodontitis. I Am Dent Assoc 1971;83:1294-6.

90. Bender IB, Naidorf IJ, Garvey G], Bacterial endocarditis: a consideration for physicians and dentists. J Am Dent Assoc 1984;109:415-20.

91. Everett ED, Hirschmann JV. Transient bacteraemia and endocarditis prophylaxis: a review. Medicine 1977; 56:61-77.

92. Guntheroth WG. How important are dental procedures as a cause of infective endocarditis? Am / Cardiol 1984;54:797-801.

93. Schroeder HE, Theilade J. Electrón microscopy of normal human gingival epithelium. J Perio Res 1966;1:95-119.

94. Lockhart PB. The risk for endocarditis in dental practice. Periodontology 2000 2000;23:127-35.

95. Seiham A, Netuvelli GS. Periodontal diseases in Europe. Periodontology 2000 2002;29:104-21.

96. Roberts G], Holzel HS, Sury MRJ, Simmons NA, Gardner P, Longhurst P. Dental bacteremia in children. Pediatr Cardiol 1997; 18:24-27.

97. Khurana M, Martin MV. Orthodontics and Infective Endocarditis. $\mathrm{Br}$ J Orthodontics 1999;26:295-8.

98. Roberts G], Simmons NB, Longhurst P, Hewitt PB. Bacteraemia following local anaesthetic injections in children. Br Dent / 1998; 185:295-8.

99. Guggenheimer J, Orchard TJ, Moore PA, Myeres DE, Rossie KM. Reliability of self-reported heart murmur history : possible impact on antibiotic use in dentistry. JADA 1998;129:861-6. 